ORIGINAL ARTICLE

\title{
Lysophosphatidic acid and sphingosine-1-phosphate promote morphogenesis and block invasion of prostate cancer cells in three-dimensional organotypic models
}

\author{
V Härmä ${ }^{1}$, M Knuuttila ${ }^{2}$, J Virtanen ${ }^{1,2}$, T Mirtti ${ }^{3,4}$, P Kohonen ${ }^{2}$, P Kovanen ${ }^{4}$, A Happonen ${ }^{5}$, \\ S Kaewphan ${ }^{6}$, I Ahonen ${ }^{2}$, O Kallioniemi ${ }^{3}$, R Grafström ${ }^{1,7}$, J Lötjönen ${ }^{8}$ and M Nees ${ }^{1}$ \\ ${ }^{1}$ Medical Biotechnology Knowledge Centre, VTT Technical Research Centre of Finland, Turku, Finland; ${ }^{2}$ Biotechnology Centre, \\ University of Turku, Turku, Finland; ${ }^{3}$ Institute for Molecular Medicine Finland (FIMM), University of Helsinki, Helsinki, Finland; \\ ${ }^{4}$ Department of Pathology, Haartman Institute, University of Helsinki and HUSLAB, Helsinki University Central Hospital, Helsinki, \\ Finland; ${ }^{5}$ Department of Signal Processing, Tampere University of Technology, Tampere, Finland; ${ }^{6}$ Department of Information \\ Technology, University of Turku, Turku, Finland; ${ }^{7}$ Laboratory for Toxicology, Karolinska Institute, Stockholm, Sweden and \\ ${ }^{8}$ Knowledge Intensive Services, VTT Technical Research Centre of Finland, Tampere, Finland
}

Normal prostate and some malignant prostate cancer (PrCa) cell lines undergo acinar differentiation and form spheroids in three-dimensional (3-D) organotypic culture. Acini formed by PC-3 and PC-3M, less pronounced also in other PrCa cell lines, spontaneously undergo an invasive switch, leading to the disintegration of epithelial structures and the basal lamina, and formation of invadopodia. This demonstrates the highly dynamic nature of epithelial plasticity, balancing epithelial-to-mesenchymal transition against metastable acinar differentiation. This study assessed the role of lipid metabolites on epithelial maturation. PC-3 cells completely failed to form acinar structures in delipidated serum. Adding back lysophosphatidic acid (LPA) and sphingosine-1-phosphate (S1P) rescued acinar morphogenesis and repressed invasion effectively. Blocking LPA receptor 1 (LPAR1) functions by siRNA (small interference RNA) or the specific LPAR1 inhibitor Ki16425 promoted invasion, while silencing of other G-protein-coupled receptors responsive to LPA or S1P mainly caused growth arrest or had no effects. The $G$-proteins $G \alpha_{12 / 13}$ and $G \alpha_{i}$ were identified as key mediators of LPA signalling via stimulation of RhoA and Rho kinases ROCK1 and 2, activating Rac1, while inhibition of adenylate cyclase and accumulation of cAMP may be secondary. Interfering with these pathways specifically impeded epithelial polarization in transformed cells. In contrast, blocking the same pathways in non-transformed, normal cells promoted differentiation. We conclude that LPA and LPAR1 effectively promote epithelial maturation and block invasion of PrCa cells in 3-D culture. The analysis of clinical transcriptome data confirmed reduced expression of LPAR1 in a subset of PrCa's. Our study demonstrates a metastasis-suppressor function for

Correspondence: Dr M Nees, Medical Biotechnology Knowledge Centre, VTT Technical Research Centre of Finland, Varsinais Suomi, PO Box 106, Turku FI 20520, Finland.

E-mail: matthias.nees@vtt.fi

Received 5 March 2011; revised 26 June 2011; accepted 28 July 2011; published online 26 September 2011
LPAR1 and $G \alpha_{12 / 13}$ signalling, regulating cell motility and invasion versus epithelial maturation.

Oncogene (2012) 31, 2075-2089; doi:10.1038/onc.2011.396; published online 26 September 2011

Keywords: prostate cancer; epithelial plasticity; bioactive lipids; G-protein coupled receptors; lysophosphatidic acid; sphingosine-1-phosphate

\section{Introduction}

The mechanisms promoting local invasion and metastasis of castration-resistant, late stage prostate cancer $(\mathrm{PrCa})$ are incompletely understood and poorly recapitulated by standard 2-dimensional (2-D) monolayer cell culture and invasion models (for example, transwell migration/Boyden chambers and scratch-wound assays). 2-D models fail to support the formation of multicellular structures and epithelial barriers such as the basement membrane (BM). In contrast, advanced model systems in three-dimensional (3-D) tumor microenvironment promote the formation of organotypic structures with relevant cell-cell and cell-matrix interactions (Brekhman and Neufeld, 2009), epithelial polarization and differentiation. In particular, models that utilize physiologically relevant ECM such as collagens or laminin (Matrigel) increasingly gain relevance (Reuter et al., 2009; Inman and Bissell, 2010; Ridky et al., 2010). 3-D cultures represent an opportunity to investigate dynamic morphogenetic processes like epithelial-tomesenchymal transition (Chu et al., 2009), a central mechanism determining tumor cell motility, invasiveness and drug resistance (Mani et al., 2008; Kalluri and Weinberg, 2009). We have recently reported a miniaturized 3-D platform to analyze the morphology of $\mathrm{PrCa}$ cell lines in laminin-rich ECM (lrECM) (Harma et al., 2010). Malignant PC-3 and PC-3M cells initially show normal acinar differentiation, but later undergo spontaneous transformation into aggressive stellate structures 
('invasive switch'). After the initial formation of invadopodia, followed by the disintegration of symmetrical spheroids and BM degradation, malignant cells invade the 1rECM as multicellular strings, concomitant with the re-organization of cell-cell and cell-matrix contacts, and altered integrin cell adhesion signalling.

Lysophosphatidic acid (LPA) and sphingosine-1phosphate (S1P) are simple, water soluble bioactive lipids that regulate diverse cellular functions like cellproliferation (Gibbs et al., 2009), differentiation (Kim et al., 2002; Bagga et al., 2004), apoptosis (Goetzl et al., 1999b; Deng et al., 2002), migration (Shida et al., 2003; Hao et al., 2007; Kim et al., 2008; Wang et al., 2008; Li et al., 2009a,b) and adhesion (Sawada et al., 2002; Smicun et al., 2007; Devine et al., 2008) in many cell types. Physiological LPA levels between $0.1-25 \mu \mathrm{M}$ are found in serum (Tigyi and Miledi, 1992), ascitic effusions (Westermann et al., 1998) and inflammatory fluids (Fourcade et al., 1995). Large amounts of LPA and S1P are secreted by platelets (Eichholtz et al., 1993), adipocytes (Valet et al., 1998) and fibroblasts (Fukami and Takenawa, 1992; Olivera and Spiegel, 1993). LPA and S1P mediate intracellular actions mainly via Gprotein-coupled receptors, encoded by the LPA-receptors LPAR1-6 and S1P receptors S1PR1-5, and coupled to stimulatory or inhibitory $\mathrm{G}$-proteins, including $\mathrm{G} \alpha_{\mathrm{i} / \mathrm{o}}$, $\mathrm{G} \alpha_{\mathrm{s}}, \mathrm{G} \alpha_{\mathrm{q}}$ and $\mathrm{G} \alpha_{12 / 13}$. Preferences for certain $\mathrm{G}$-protein utilization depend on the receptors, cell environment, differentiation and adaptation to acute stress/signalling conditions. LPA and S1P receptors trigger intracellular signalling cascades such as $\mathrm{Ca}^{2+}$ mobilization (Meyer zu Heringdorf et al., 1998), activation of the Rho-GTPases, accumulation of cytoplasmic cAMP and actin rearrangement, resulting in dramatic changes of cell morphology and motility (van Dijk et al., 1998). LPA and S1P are associated with the progression of malignancies including ovarian (Hong et al., 1999; Fang et al., 2002), breast (Goetzl et al., 1999a; Nava et al., 2002) and colorectal cancers (Shida et al., 2004; Kawamori et al., 2006). However, their functions and relevance in PrCa progression, invasion and motility remain controversial (Gibbs et al., 2009; Zeng et al., 2009). Here, we investigated the roles of LPA and S1P, their cognate G-protein-coupled receptor's (Guo et al., 2006) and downstream signalling pathways (Li et al., 2005) that regulate the switch between acinar morphogenesis and invasion.

\section{Results}

Cell density and delipidated serum promote invasion in 3-D The dynamics of the initial normal-like spheroid phase formed by PC-3 cells and their spontaneous transformation into invading structures were affected by external factors, including cell density. PC-3 cells were transferred into 3-D microwells at increasing cell densities. Sparsely seeded cells (500-1000 cells/well) develop large, hollow spheroids lacking invasive processes for $>12$ days (Figure 1a, measured for $144 \mathrm{~h}$ ). Onset of invasion is indicated by the loss of 'roundness', as measured by automated image analysis (ACCA). At high density ( 2500 cells/well), invasion commences preferentially in dense areas at earlier time points. Adding fresh medium to invasive $3-\mathrm{D}$ cultures results in temporary retraction of invasive processes.

Next, medium was supplemented with increasing quantities of fetal bovine serum (FBS). In the absence of FBS, cells failed to form round spheroids, and invaded the 1rECM from day 1 (Figure 1b). FBS concentrations $>2.5 \%$ supported acinar morphogenesis and suppressed invasive behavior, indicating that differentiation-promoting factors were sufficiently supplied by $2.5 \%$ FBS. In contrast, cultures supplemented with charcoal-delipidated serum (CSS), removing the most lipophilic components including LPA and S1P (Lee et al., 1998a, 1998b), failed to develop spheroids even at 20\% FBS (Figure 1c). This indicates repression of invasive properties by lipophilic factors.

\section{The bioactive lipids LPA and SIP promote epithelial maturation and suppress invasive transformation}

To identify the postulated lipophilic regulators, we tested a panel of steroids, growth factors and vitamins (Supplementary Figure S1). Re-constitution of androgens, estrogens, progesterone, glucocorticoids, vitamin A (retinoic acid) or $\mathrm{D}_{3}$ (cholecalciferol) failed to support acinar differentiation. Next, we investigated lipids found at significant concentrations in serum, plasma and lymphatic fluids (prostaglandins, eicosanoids and thromboxanes). Only addition of LPA and S1P effectively suppressed invasion (Figure 2), maintaining differentiation, polarization and complete BM. LPA was less potent than S1P, with strong invasion-suppressive effects for $36 \mathrm{~h}$ and $42 \mathrm{~h}$ at 1.0 and $10 \mu \mathrm{M}$, respectively (Figure $2 \mathrm{a}$ ). With $\mathrm{S} 1 \mathrm{P}$, effects lasted for $>100 \mathrm{~h}$ (Figure $2 \mathrm{~b}$ ). In delipidated medium (Figure 2c, CSS), the BM started to disintegrate after $24 \mathrm{~h}$ and was completely disrupted after $72-96 \mathrm{~h}$ (compare also Figure 6). Both LPA and S1P potently repressed $\mathrm{BM}$ degradation and invasion. However, high concentrations of S1P, but not LPA, caused morphological defects and disorganization of the spheroids. Both LPA and S1P are thus potent regulators of acinar maturation, while S1P also affects cell growth and survival. LPA and S1P also potently blocked cell motility in monolayer settings, as shown by wound-healing assays (Supplementary Figure S2A).

\section{LPAR1 mediates invasion-inhibiting signals, while} LPAR2 and S1PR2 promote cell growth and proliferation Next, we tested if siRNA knock down of the LPA and $\mathrm{S} 1 \mathrm{P}$ receptors compromises the invasion-blocking effects of LPA and S1P (Figure 3a). The receptors LPAR1-3 and S1PR2-4 were silenced by RNA interference in monolayer culture for $72 \mathrm{~h}$, and subsequently transferred into 3-D 1rECM culture. The silencing effect of each siRNA was validated by RT-PCR. Knock down of LPAR1 in the presence of LPA or blocking of LPAR1 with the selective compound $\mathrm{Ki}-16425$ (Figure $3 \mathrm{~b}$ ) caused rapid increase of invasiveness (loss of 'roundness' after $24 \mathrm{~h}$, in contrast to 


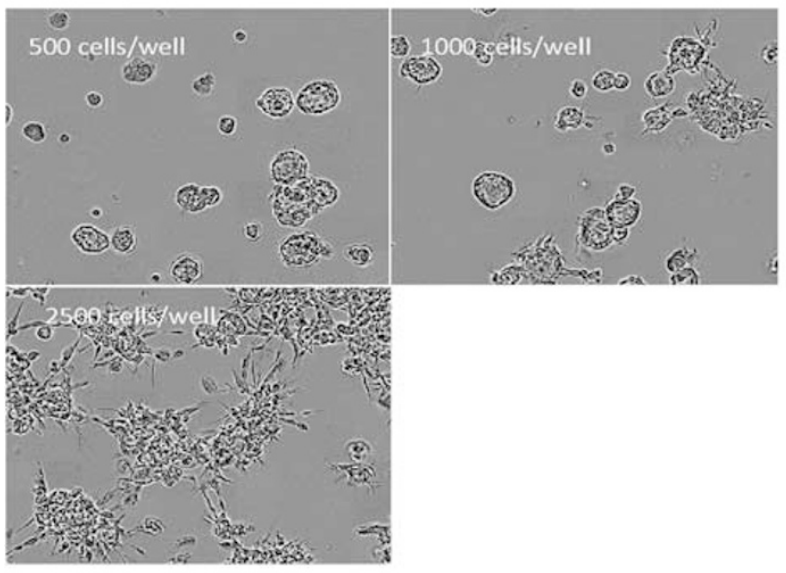

b

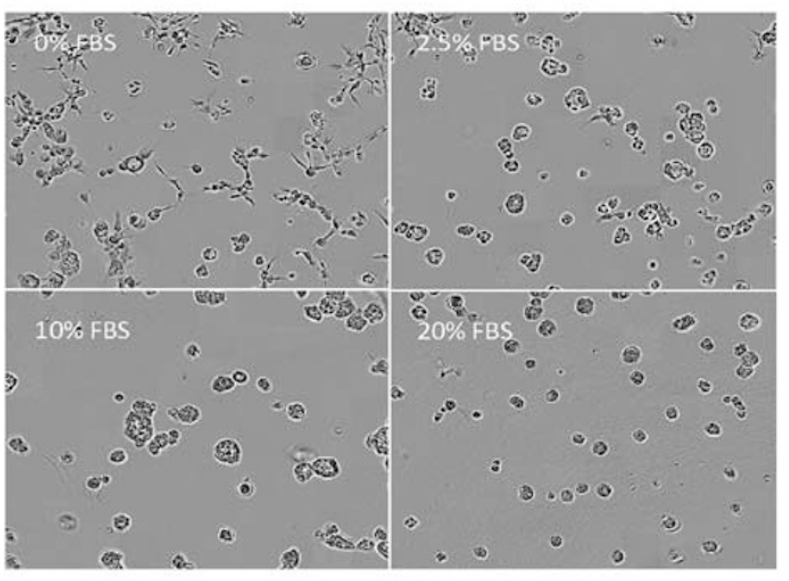

C

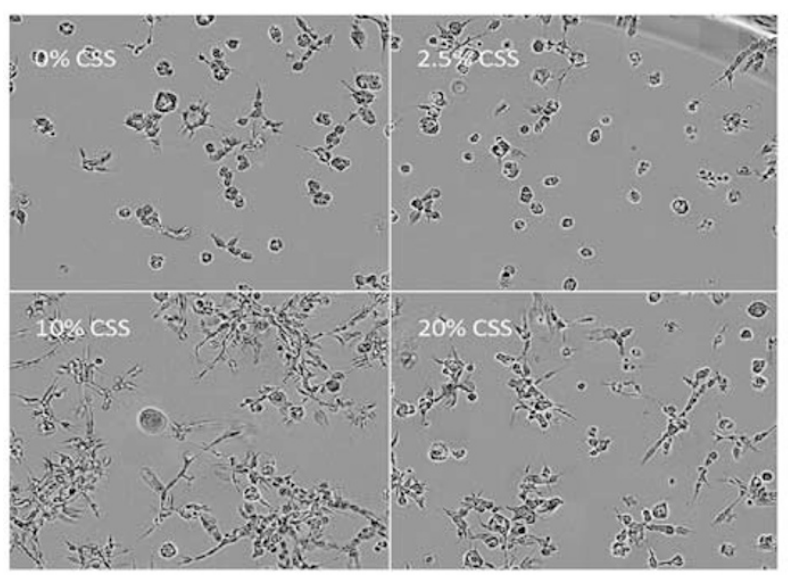

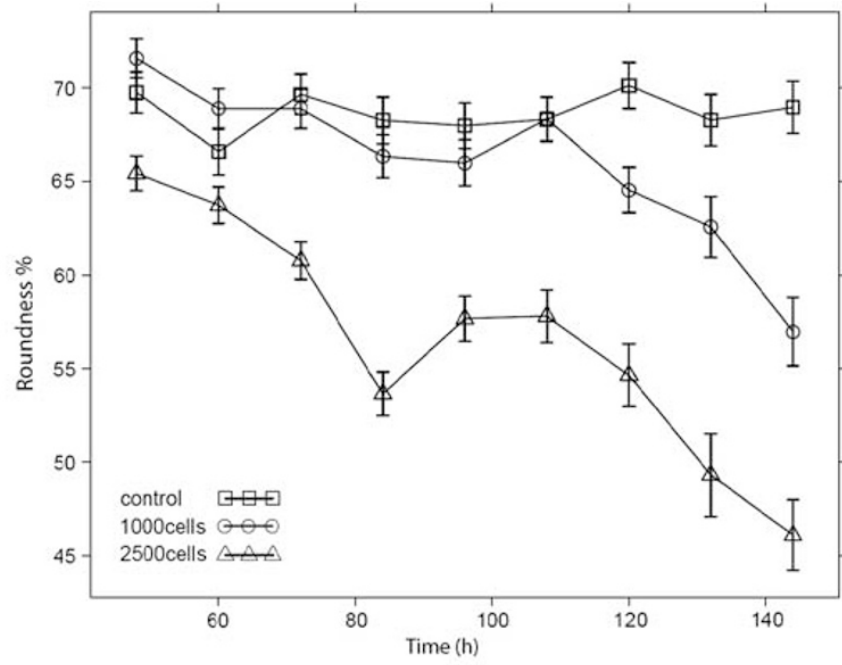
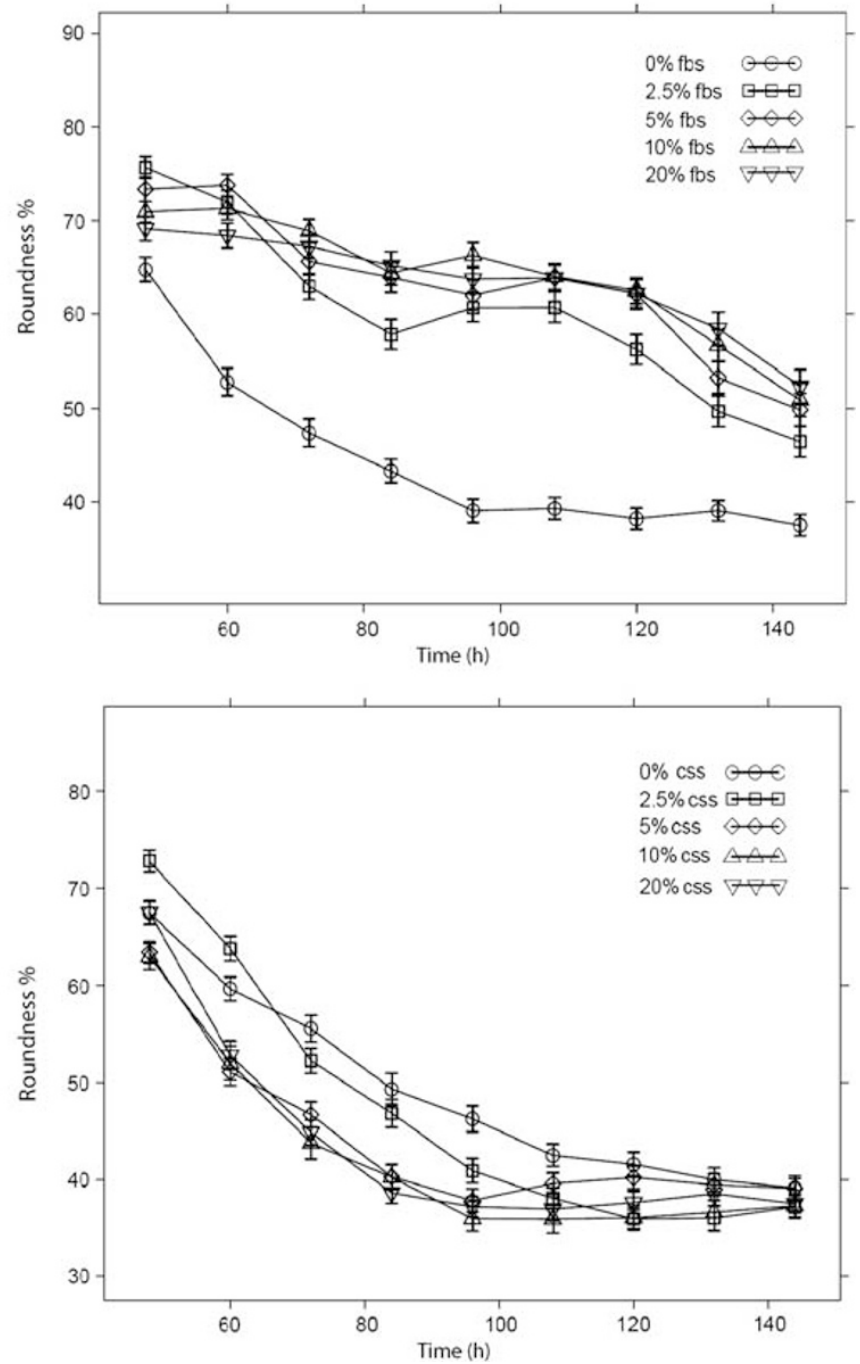

Figure 1 Factors supporting the invasive switch of acini formed by PC-3 cells in organotypic 3-D culture. (a) Increasing cell density promotes conversion of differentiated acini into invasive structures (phase-contrast images from live cell imaging; left panel). Disintegration of spheroids and invasive properties measured as loss of roundness by automated image analysis software ACCA (right panel; measured from days 4-7 of culture). (b) Addition of $>2.5 \%$ FBS supports differentiation and suppresses invasive transformation of acini in 3-D. (c) FBS deprived of lipids by charcoal-stripping (CSS) fails to support differentiation even at $20 \%$. 

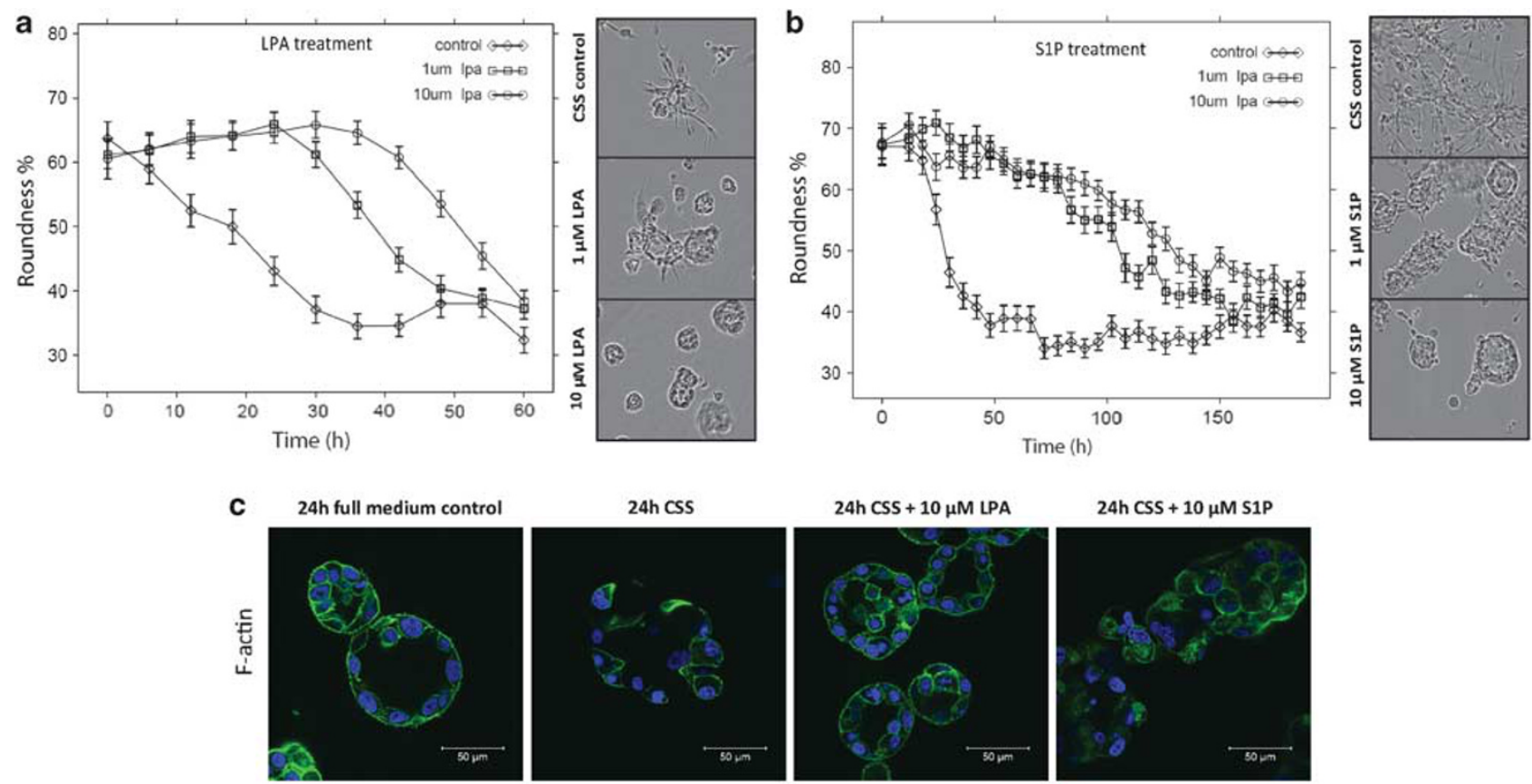

$24 \mathrm{~h}$ CSS $+10 \mu \mathrm{M}$ LPA
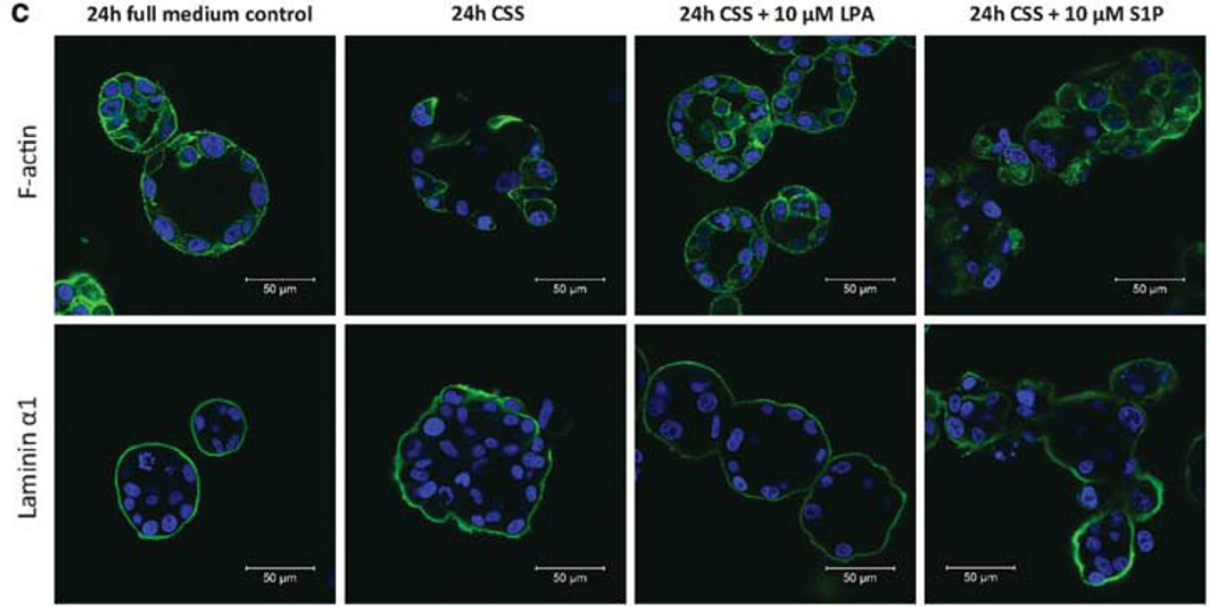

Figure 2 Supplementing bioactive lipids LPA and S1P to CSS supports acinar differentiation and represses invasive transformation. (a) Concentrations of 1 and $10 \mu \mathrm{M}$ LPA effectively repress invasive properties in lrECM for 36 and $42 \mathrm{~h}$, respectively, maintaining the round phenotype. (b) S1P concentrations of 1 and $10 \mu \mathrm{M}$ in CSS repress invasiveness for close to $100 \mathrm{~h}$. (c) Immunofluorescent images of PC-3 spheroids stained for filamentous actin (F-actin) and laminin $\alpha-1$ demonstrate disintegration of the actin cytoskeleton and first indication of the beginning disintegration of the BM after $24 \mathrm{~h}$ exposure to $10 \%$ lipid-deprived CSS versus complete medium. In CSS supplemented with $10 \mu \mathrm{M}$ LPA or $1 \mu \mathrm{M}$ S1P, both actin cytoskeleton and BM remain intact.

scrambled siRNA), but did not affect cell growth. In contrast, siLPAR2 resulted in proliferation-block. Similarly, in 2-D conditions, silencing of LPAR 1 and 2 caused minor effects on cell proliferation (Supplementary Figure S2B). LPAR3 silencing did not result in a clear phenotype (not shown). Thus, LPAR1 appears as the key factor in LPA-mediated block of invasion, and both LPA and S1P can act via this receptor. Silencing of S1P receptors 2, 3 and 4 in 2-D and 3-D conditions caused growth inhibition (Supplementary Figure S2B), but did not affect invasion (Figure 3c; loss of 'roundness'). The growth-promoting effect of S1PR2 was further validated with the specific antagonist JTE-013, causing severe growth retardation (not shown). As S1PR1-silencing was ineffective, we used the specific antagonist W146, which did not affect invasiveness (not shown).

G-protein signalling cascades downstream of LPA and $S I P$ receptors affect $P C-3$ spheroid formation and invasive switch

Gene set enrichment analysis (Figure 4a, Supplementary Table 1) (Mootha et al., 2003; Subramanian et al., 2005) of mRNA expression data, comparing PrCa cells in 2-D monolayer with early time points in 3-D culture (days 4-8), showed that a number of canonical pathways, gene sets and gene ontology categories were significantly enriched in all $\mathrm{PrCa}$ cell lines growing in 3-D (Harma et al., 2010), a characteristic of acinar morphogenesis. Most significantly induced were Rho-stimulatory $\mathrm{G} \alpha_{12 / 13}$ and $\mathrm{G} \alpha_{\mathrm{q}}$ signalling, whereas adenylate-cyclase activating $\mathrm{G} \alpha_{\mathrm{s}}$ signalling was reduced. Also adenylate-cyclase inhibitory $G \alpha_{i}$ signalling was induced, but failed false discovery rate filtering. A detailed analysis of genes within the $G \alpha_{12 / 13}$ pathway (heatmap Figure $4 \mathrm{~b}$ ) indicated that the Rho-kinases ROCK1 + 2, G-protein

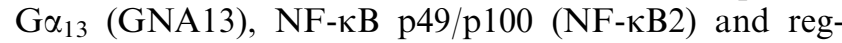
ulatory members of the $\mathrm{NF}-\kappa \mathrm{B}$ transcription factor

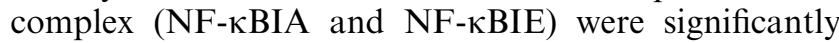
increased in 3-D compared with 2-D culture, peaking at days 4-8 when spheroids mature. As illustrated by Supplementary Figure S3, differential expression also occurred for many key components downstream of the $\mathrm{G} \alpha_{12 / 13}$ pathway. In invading cells $(\mathrm{d} 13+15)$, expression of most $\mathrm{G} \alpha_{12 / 13}$ related transcripts is subsequently reduced. Silencing of GNA12 (Figure 4c) caused cell elongation in 2-D and severe growth defects in 3-D, 


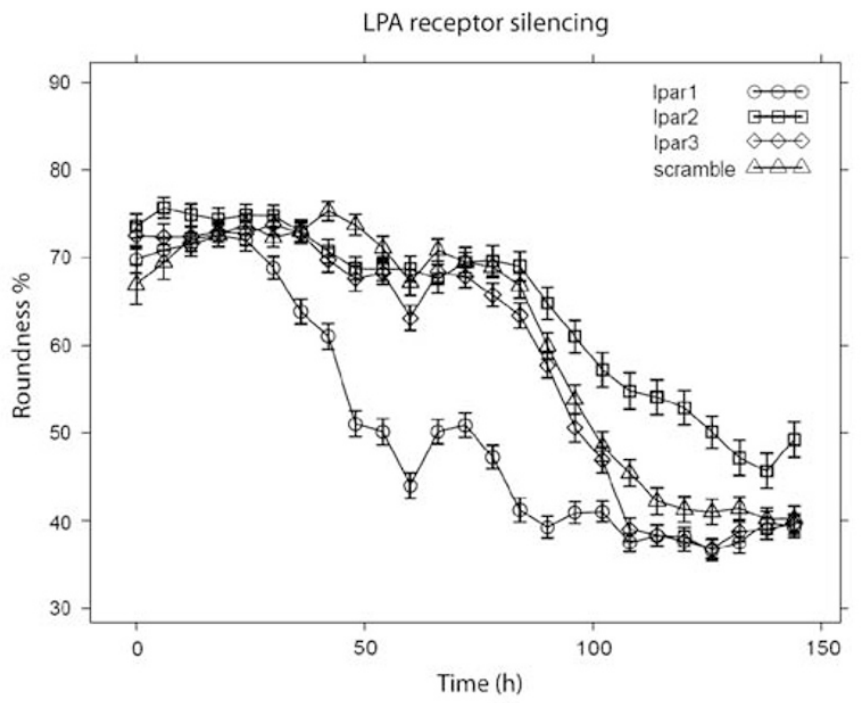

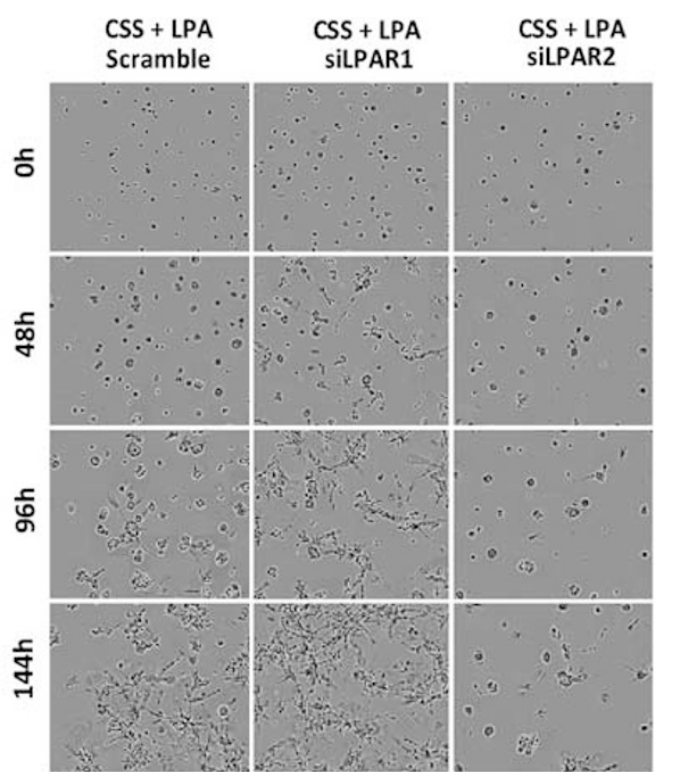

b

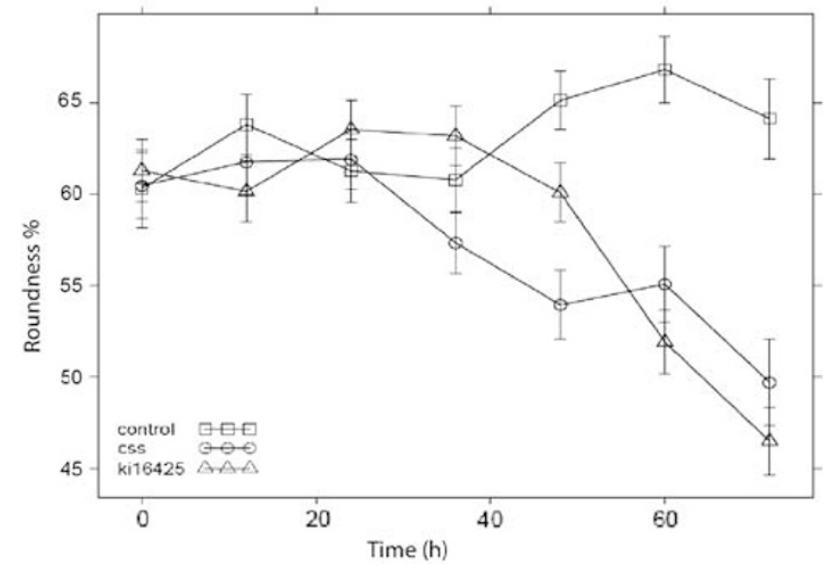

C

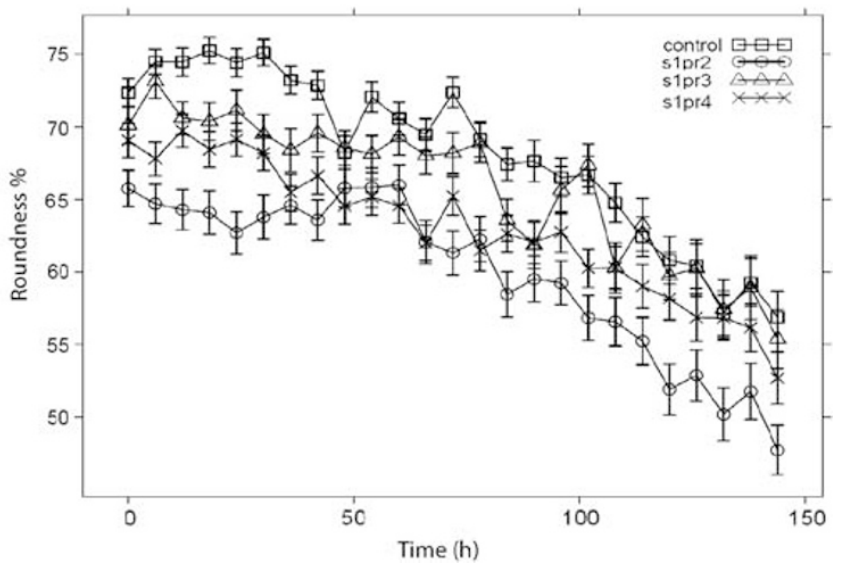

Figure 3 Silencing of LPA receptor 1 abolishes the invasion-inhibitory functions of LPA. (a) siRNA silencing of LPA receptors: siLPAR1 abolishes repression of invasive properties by LPA, whereas siLPAR3 has no effect (graph). LPAR2 silencing is growthinhibitory (right panel). (b) Inhibition of LPAR 1 and 3 with the specific inhibitor Kil6425 effectively blocks acinar differentiation in complete medium supplemented with 10\% FBS (control), resulting in phenotypic outcome identical to CSS. (c) Silencing of S1P receptors, S1PR3 and 4, does not affect invasive properties, and siS1PR2 results in growth retardation.

indicating the importance of $\mathrm{G} \alpha_{12 / 13}$ signalling in spheroid formation. Similar results were observed with siGNA13 (not shown), which was slightly less effective in 3-D. Furthermore, a detailed analysis of gene expression associated with LPAR1 functions (Figure 4d) indicates a peak of expression at days $4+8$, followed by a decline in invasive cells (days $13+15$ ) and failure of induction in CSS-treated spheroids.

\section{Blocking the $G \alpha_{12 / 13}$ RhoA/ROCK pathway induces invasive properties in 3-D}

We executed a small-scale compound screen, based on inhibitors and activators targeting G-proteins and downstream signalling (Figure 5a, upper panel; Supplementary Table 2). Modulators of RhoA and Rho-kinases ROCK $1 / 2$ altered invasive properties in both 3-D and 2-D conditions (Supplementary Figure S4). The RhoA inhibitor CCG-1423 blocked invasion, but resulted in growth retardation, indicating a role for RhoA in proliferation. In cells treated with ROCK inhibitors Y-27632 and HA-1100, invadopodia formed within $24 \mathrm{~h}$, similar to CSS treatment, silencing or biochemical blocking of LPAR1. Disrupting actincytoskeleton polymerization with cytochalasin-D caused substantial growth retardation, but the remaining structures showed pro-invasive structures. ROCK inhibitors effectively promoted motility in 2-D woundhealing/scratch-wound assays (Supplementary Figure S4A). These results indicate that LPA, LPAR1, G $\alpha_{12 / 13}$, Rho proteins and downstream effectors are fundamental for the maturation of spheroids. Blocking these pathways promotes cell elongation, invadopodia formation and invasive/migratory properties. 
a

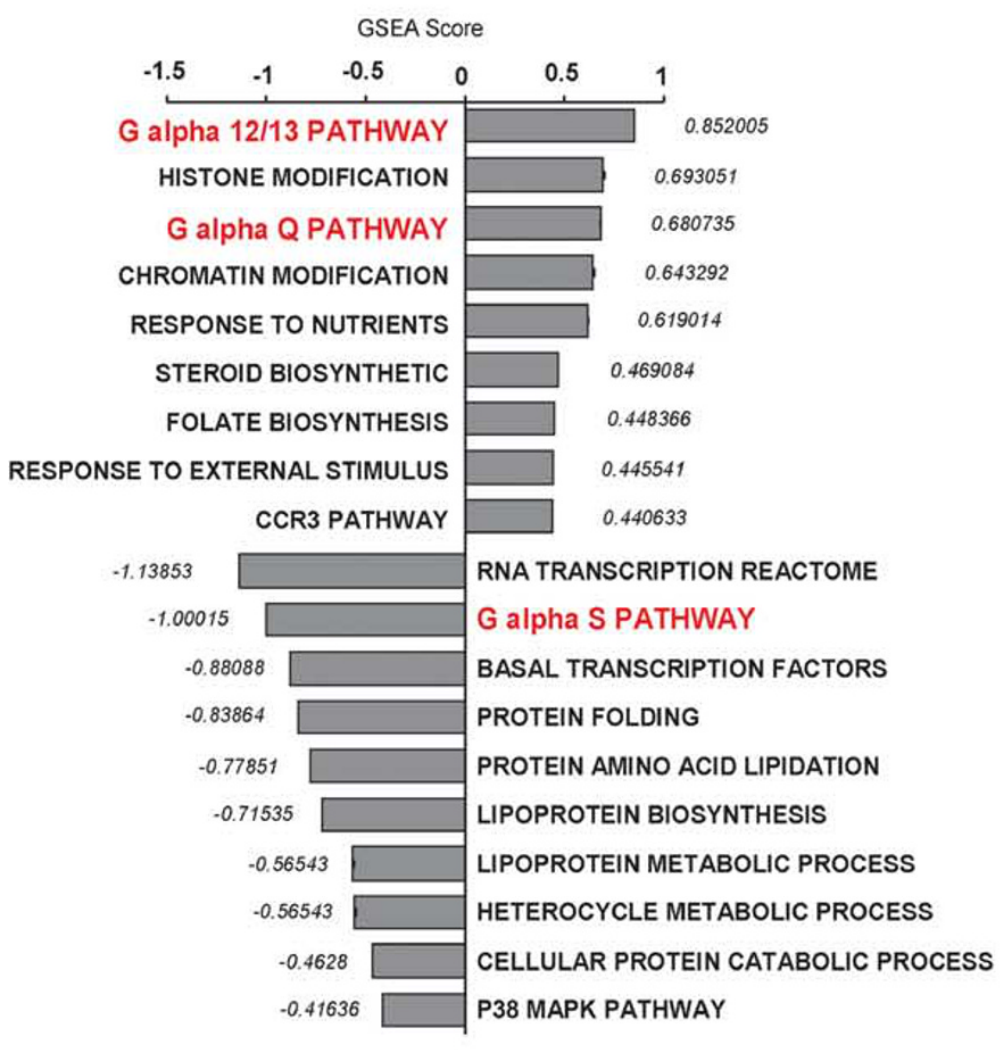

C

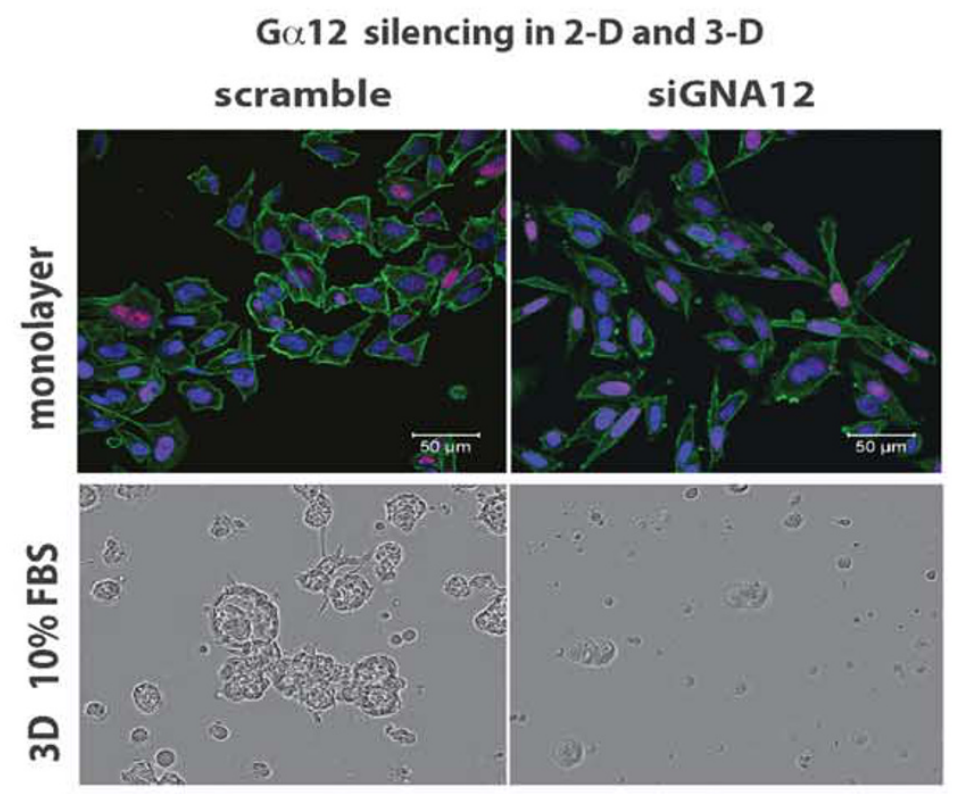

b

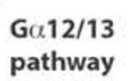

$$
\text { pathway }
$$
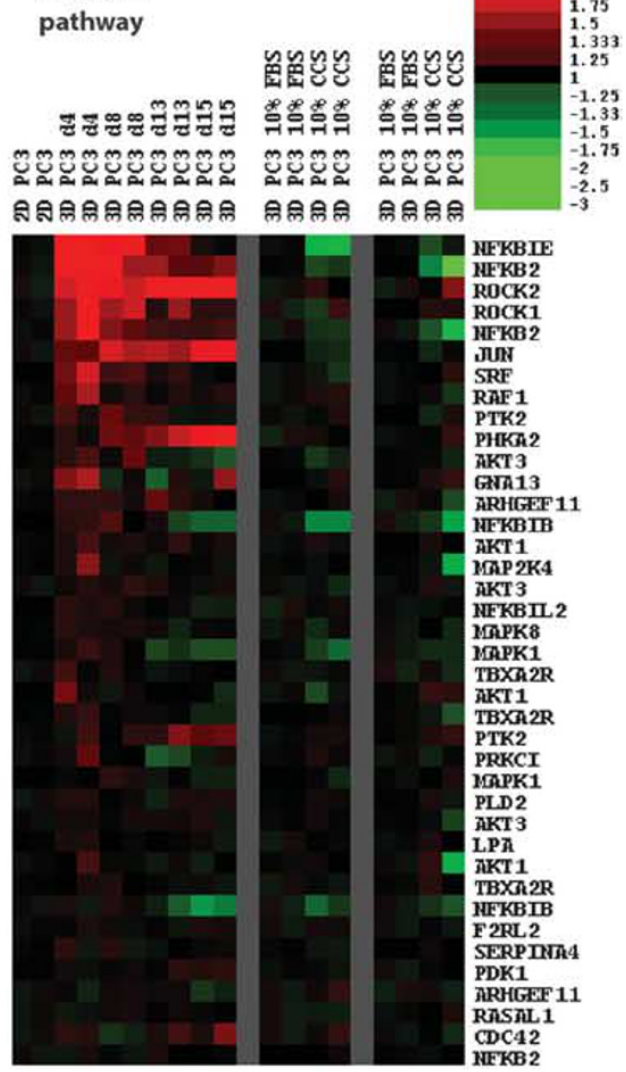

d LPAR1 pathway

สำ สำ

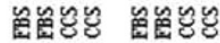

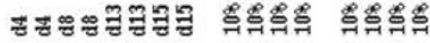

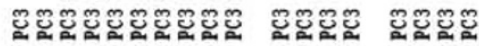

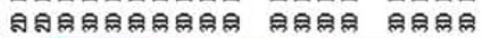

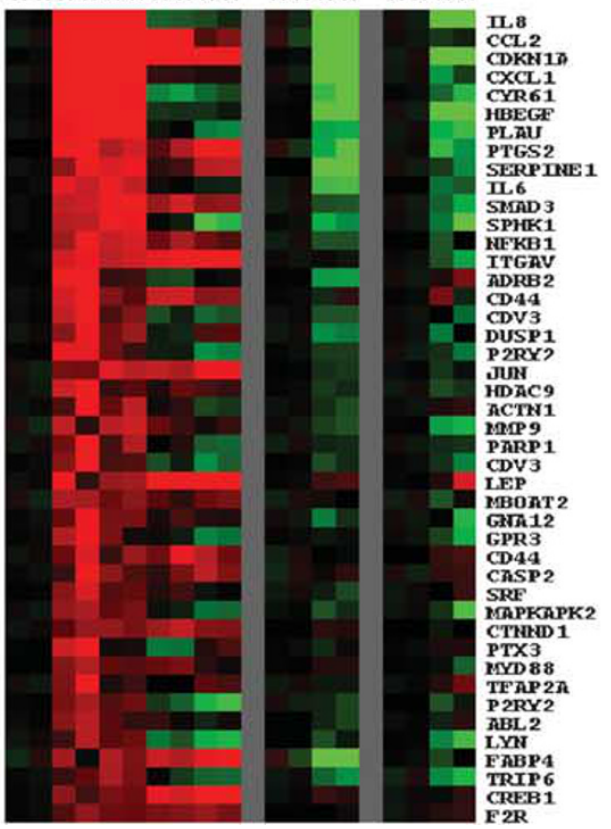


Activating the $G \alpha_{s} /$ adenylate cyclase/cAMP pathway promotes invasion in 3-D

LPAR1 was reported to mediate downstream actions via $\mathrm{G} \alpha_{\mathrm{q}}$ and $\mathrm{G} \alpha_{\mathrm{i}} / \mathrm{o}$ proteins; together with $\mathrm{G} \alpha_{12 / 13}$ these counteract the stimulatory activity of $\mathrm{G} \alpha_{\mathrm{s}}$ signalling. Therefore, we tested modulators of $\mathrm{G} \alpha_{\mathrm{s}}$ downstream signalling pathways: activity of adenylate cyclase (AC) and phospholipase $\mathrm{C}$, increased intracellular cAMP levels, protein kinase A (PKA) and the ERK1/2 kinases (not shown). The $\mathrm{G} \alpha_{\mathrm{i} / \mathrm{o}}$ inhibitors, pertussis toxin and NF023, or $\mathrm{G} \alpha_{\mathrm{i} / \mathrm{o}}$ effectors melittin and mastoparan, had only minor effects, possibly due to sequestration of peptides in matrigel. Treatment of spheroids with forskolin, a drug that activates AC and increases intracellular cAMP levels, resulted in a profound loss of acinar morphology and invasion (Figure 5a, lower panel), and an approximately 10-fold increase of intracellular cAMP levels (not shown). Accordingly, suppressors of cAMP accumulation (BPIPP and SQ22536) and PKA (KT-5720) effectively blocked invasion and promoted epithelial maturation. However, we detected only minor changes of intracellular cAMP levels in response to CSS, or in response to LPA and S1P, suggesting that this mechanism may only have a secondary role in downstream LPAR1 signalling. Possibly for this reason, modulators of $\mathrm{CAMP} / \mathrm{AC}$ had only little effects on cell motility (Supplementary Figure S4B) or proliferation (Supplementary Figure S4C) in 2-D wound-healing assays, in contrast to RhoA/ROCK inhibitors.

Morphologic effects of compounds were analyzed by automated and computational image analysis (Figure $5 \mathrm{~b}$ and Supplementary Figure S4. In Figure 5b, \% roundness is used as representative measure for spheroid maturation, typically resulting in round structures, and usually strongly anti-correlated with measures for invasive structures. The box and whisker plots indicate deviation from the mean (control) as the result of lipid depletion (CSS), and inhibition of G-proteins or downstream effectors. Treatment with modulators of $\mathrm{G} \alpha_{\mathrm{o} / \mathrm{i}}$ did not cause measureable changes. ROCK inhibitors (HA-1100 and Y-26732) show strong invasion-promoting effects (= reduced roundness). In contrast, RhoAinhibitor CCG-1423 blocks mainly proliferation and results in small, round structures. Promoting $\mathrm{AC}$ activity and increased cAMP accumulation favor invasiveness and reduce roundness (forskolin), while AC/PKA inhibitors increase maturation \& roundness (BPIPP, KT5720 and SQ22536). The results of treatments on morphometric parameters are illustrated by segmented images (proprietary ACCA image analysis software), corresponding to the $3-\mathrm{D}$ compound treat- ments (Supplementary Figure S5A). The heatmap (Supplementary Figure S5B, left panel) illustrates numerical changes of morphological image data for various treatments that affect invasive processes (roundness and area versus roughness, invasion-index, number, length or median). Supplementary Figure S5B, right panel, shows the Bonferroni-corrected $P$-values for these changes.

RhoA is counteracted by Rac and CDC42 proteins. Thus, we treated 3-D spheroids of PC-3 cells with Rac-inhibitors EHT-1864 (Shutes et al., 2007; Onesto et al., 2008) and NSC-23766 (Akbar et al., 2006; Devine et al., 2008), which blocked invasion effectively. This indicates a role of Rac proteins in formation of invasive structures, counteracted by RhoA in non-invasive and differentiating spheroids. We performed western blot analysis of PC-3 cells cultured in monolayer, compared with non-invasive early (d5), pre-invasive late acinus stage (d8) and invasive cells (d14) in 3-D. Furthermore, we analyzed invasive PC-3 aggregates in CSS versus acini, rescued with LPA (Figure 5d). RhoA activity, indicated by high levels of inactive p-RhoA Ser-188, is temporarily decreased in late-stage, pre-invasive acini (d8) and CSS treatment, but increased in cells rescued with LPA. Concomitantly, Racl is increased in both $\mathrm{d} 14$ invasive structures and CSS treatment, but reduced in LPA-rescued spheroids. Expression of ARHGAP1 (Rho-GTPase activating enzyme), which negatively regulates RhoA functions, is increased in $\mathrm{d} 8$ pre-invasive and $\mathrm{d} 14$ invasive structures, high in CSS-treated, but again repressed in LPA-rescued cultures. In contrast, ARHGEF11 (Rho guanine nucleotide exchange factor 11), which interacts with $\mathrm{G} \alpha_{12 / 13}$ proteins and stimulates RhoA functions, is low in monolayer and CSS treatment; but induced in early (d5) and late (d8) acini, as well as in LPA-rescued spheroids. Serum-response factor (SRF) expression corresponds most consistently with motility and invasiveness of PC-3 spheroids, and is highest in monolayer, invasive (d14) spheroids and CSS-treated cultures. The lack of changes of p-CREB1 may indicate the secondary nature of altered cAMP levels in response to LPA, as described above.

\section{Tumor-specific effects of cAMP activation and ROCK inhibition in $\operatorname{PrCa}$ cell lines}

To investigate whether the conspicuous morphological effects in response to lipid deprivation, AC/cAMP activity and ROCK inhibition are exclusive for PC-3 cells, we tested a panel of additional cell lines (Figure 6 and Supplementary Figure S6), including malignant (LNCaP and DU145) and non-transformed, immortalized prostate

Figure 4 Evaluating the roles of G-protein signalling cascades and downstream pathways. (a) Gene Set Enrichment Analysis of mRNA gene expression data from PC-3 cells at early time points (day 4-8) of 3-D organotypic culture. Factors indicate relative enrichment of gene sets in 3-D compared with 2-D culture. Altered G-protein related signalling pathways highlighted in red. (b) Heatmap of mRNA gene expression data, illustrating relative changes for genes within the G $\alpha_{12 / 13}$ pathway in PC-3 cells at various time points in 3-D culture, relative to monolayer. Multiple genes like ROCK1 are induced in well-differentiated spheroids (d4 and d8), but reduced after the invasive switch (d13 and d 15). Inducible expression is abolished in 3 -D culture supplemented with $10 \%$ CSS ( 24 and $72 \mathrm{~h}$ ). (c) Silencing of $\mathrm{G} \alpha_{12}$ protein in 2-D monolayer conditions induces spindle-like morphology of PC-3 cells (upper panels). In contrast, silencing of $\mathrm{G} \alpha_{12}$ in 3-D condition causes growth inhibition. (d) Heatmap of LPA receptor-associated genes at various time points of 3-D culture and FBS versus CSS medium. 


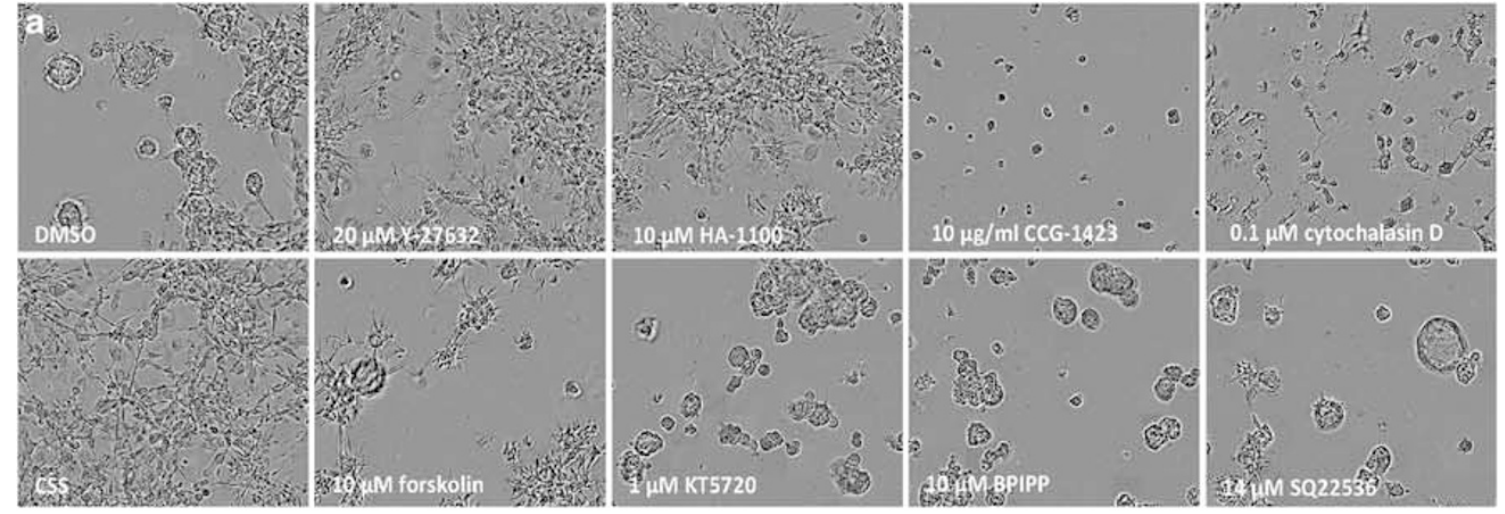

b

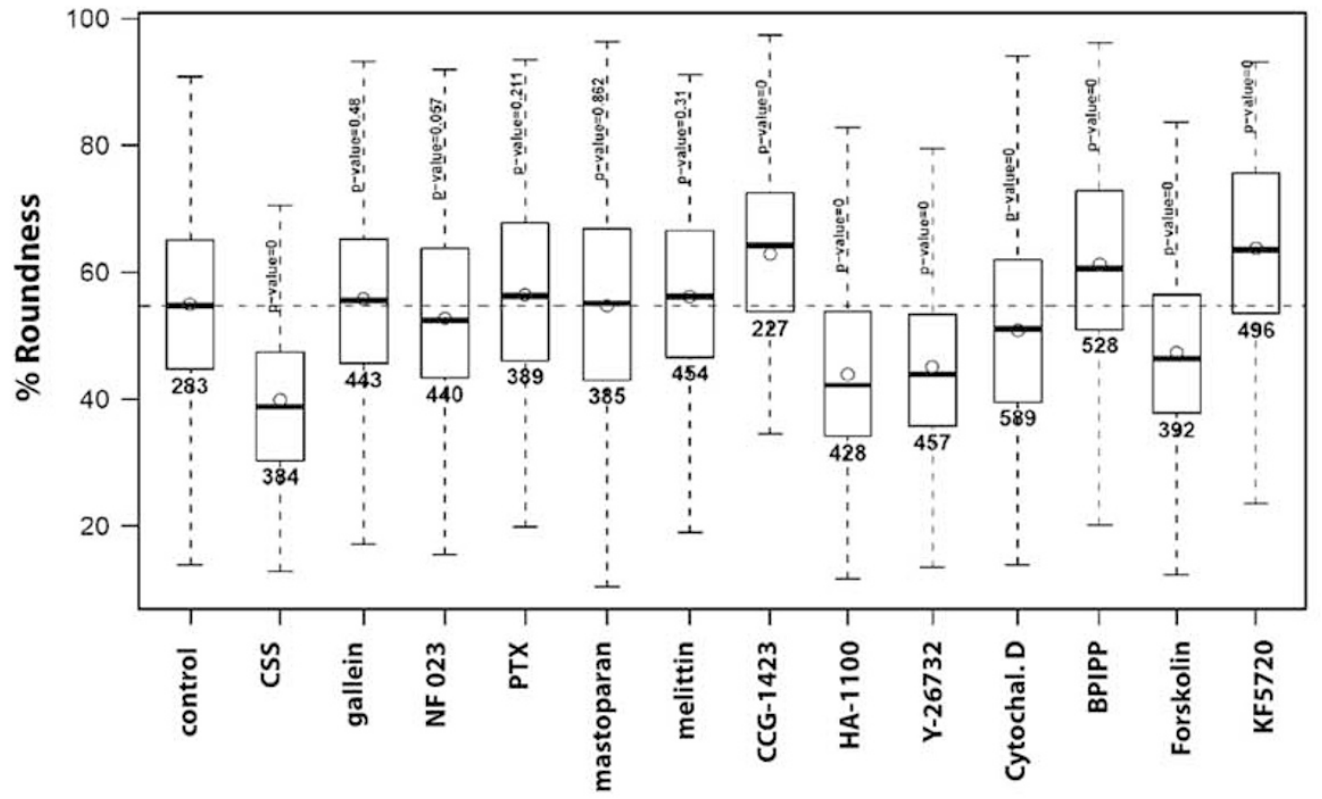

c

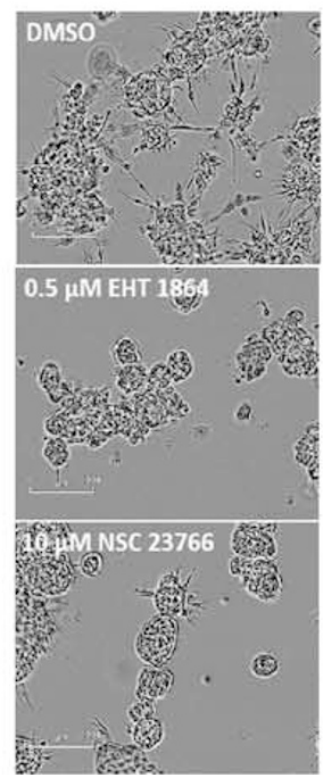

d

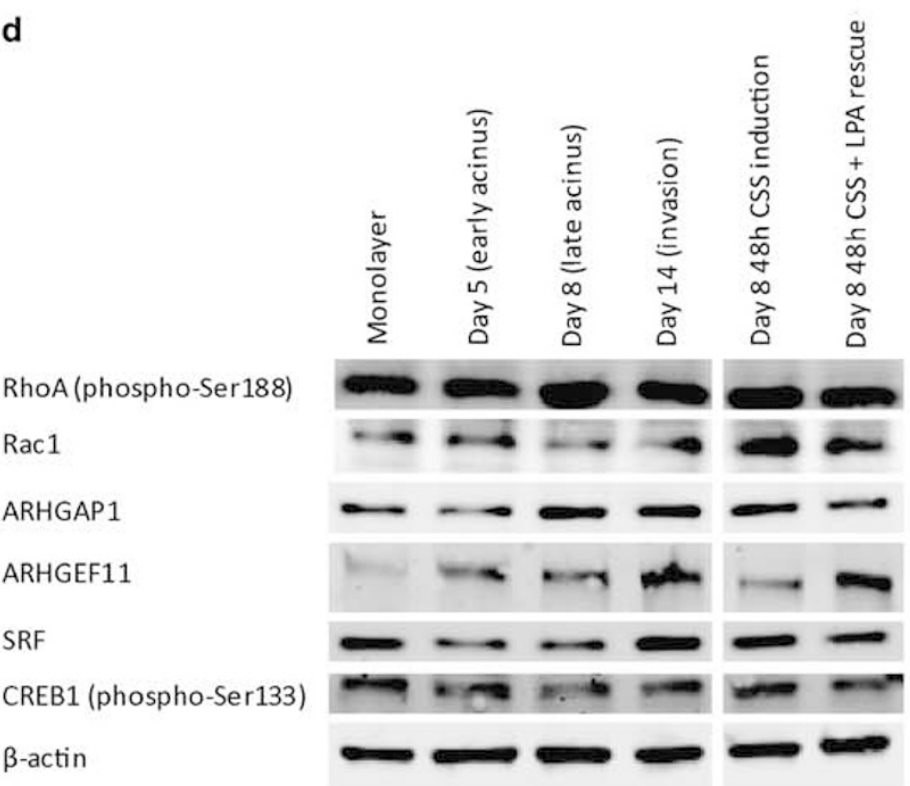

RhoA (phospho-Ser188)

Rac1

ARHGAP1

ARHGEF11

SRF

CREB1 (phospho-Ser133)

$\beta$-actin 
epithelial cell lines (EP156T and RWPE-1). CSS, the ROCK inhibitor Y-27632 and forskolin increased the otherwise limited invasive properties of malignant LNCaP cells. In contrast, treatment of non-transformed EP156T cells promoted the maturation of highly symmetrical spheroids, a hollow lumen, polarized epithelial layers, and an even more complete BM (Figure 6), Also, pre-malignant RWPE-1 and malignant DU145 spheroids responded to CSS, Y-27632 and forskolin, with the formation of invadopodia and degradation of the BM (Supplementary Figure S6). Our findings indicate that RhoA/ROCK and cAMP/
AC/PKA pathways are differentially regulated in transformed versus non-transformed cell lines, resulting in opposing morphologic responses.

\section{LPARl is downregulated in metastatic PrCa}

We next analyzed the expression of LPA and S1P receptors in clinical $\mathrm{mRNA}$ expression sets (Figure 7). In both the expO and the MSKCC transcriptome datasets, expression of LPAR1 is reduced in PrCa versus normal tissues, and anti-correlates with clinical parameters associated with cancer progression and poor
PC-3
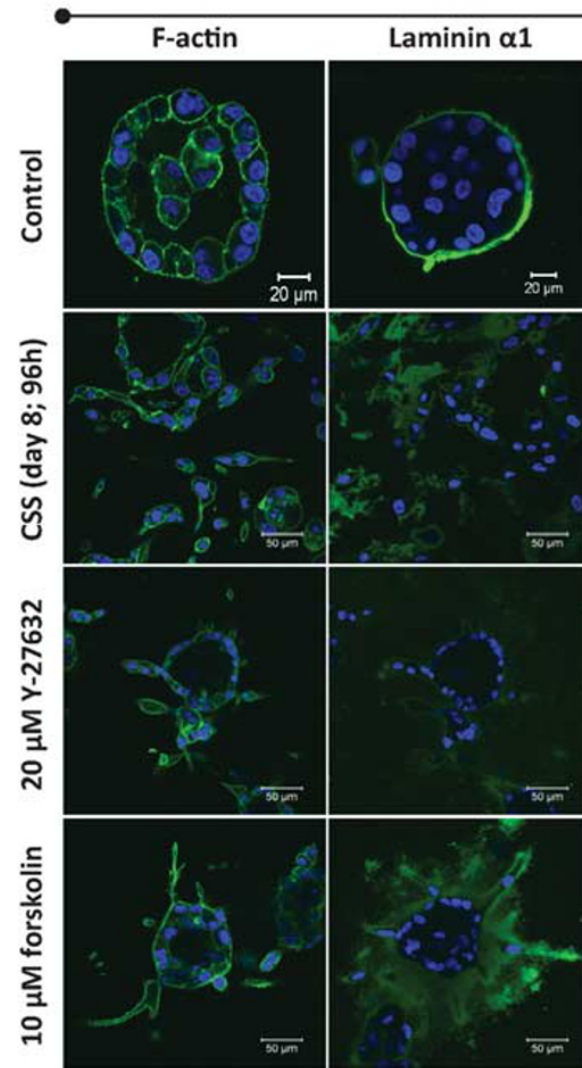

LNCaP
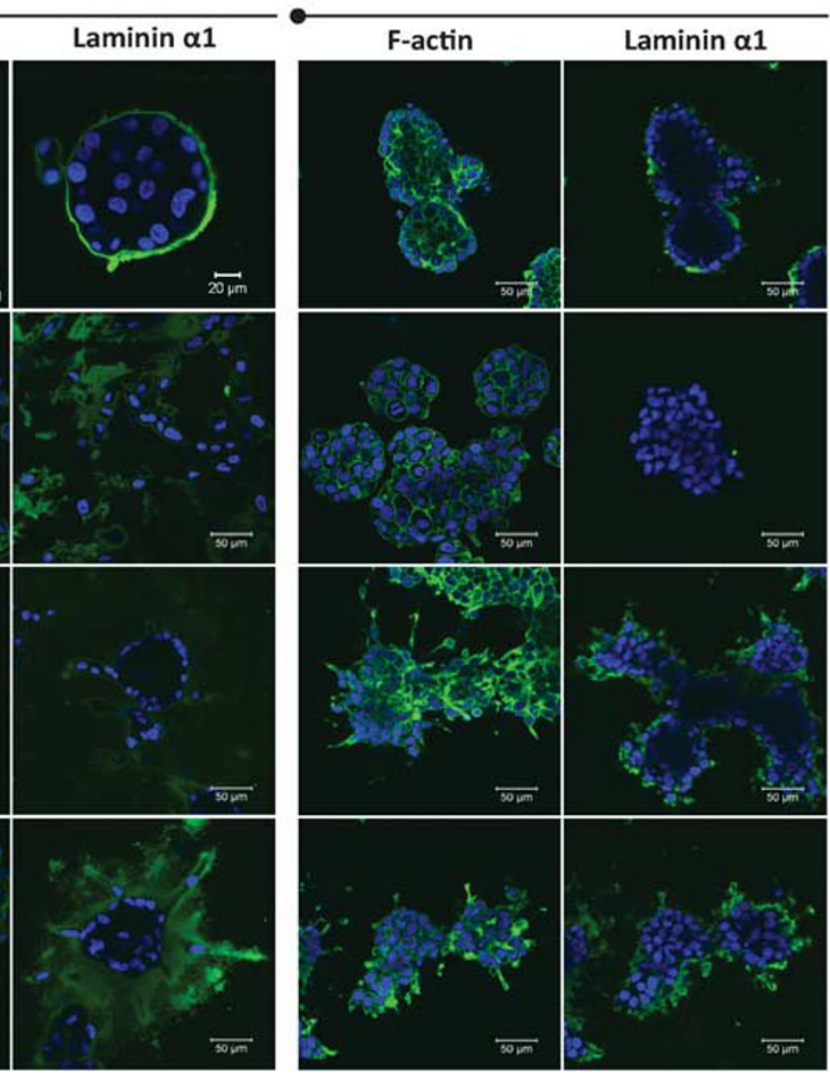

Laminin $\alpha 1$
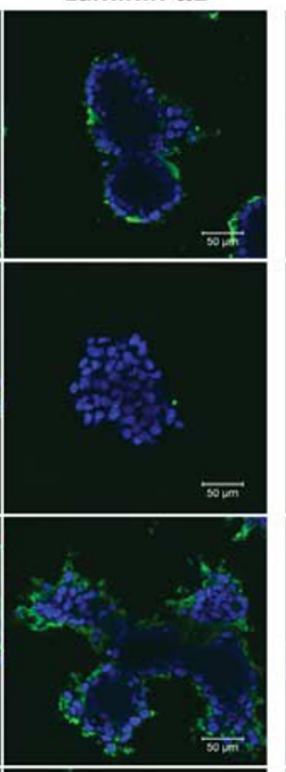

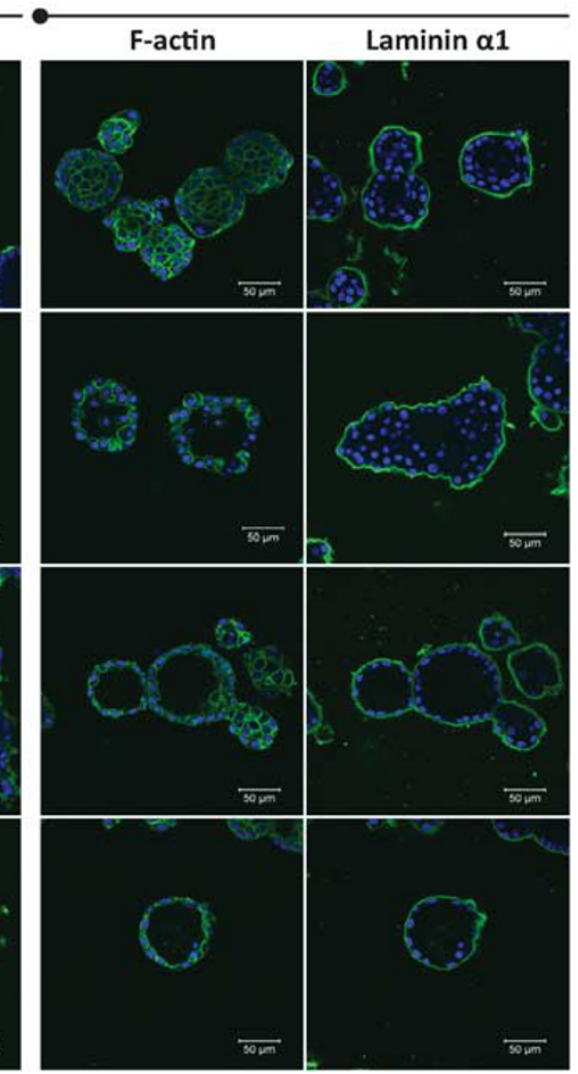

EP156T

Figure 6 Cell line-specific effects of ROCK inhibitors and increased cAMP levels on acinar morphogenesis versus formation of invasive structures. Spheroids formed by PC-3, LNCaP and EP156T cells in Matrigel were stained with Alexa488-phalloidin for filamentous F-actin, and an antibody against human laminin- $\alpha 1$ to highlight the BM. Inhibition of ROCK kinases (Y-27632) and enhanced AC/increased cAMP levels (forskolin) induce invasive features and disintegration of the BM in transformed PC-3 and LNCaP spheroids, but promote maturation of non-transformed EP156T cells.

Figure 5 Morphologic effects of compounds that modulate G-protein activity and key downstream signal transduction pathways. (a) Upper panel: Compounds blocking RhoA/ROCK pathway induce invasiveness similar to LPA and S1P depletion, LPAR1 knockdown or biochemical inhibition (upper panel; ROCK inhibitors Y-27632 and HA-1100). Direct inhibition of RhoA (CCG-1423) and actin-cytoskeleton formation (cytochalasin D) cause proliferation-defects. Lower panel: Compounds that increase (forskolin) or reduce intracellular cAMP levels (KT5720 and BPIPP) by modulating AC functions affect invasive conversion. (b) Analysis of morphologic effects on spheroids, measured by the ACCA image analysis software. Altered morphology is indicated as \% roundness, a measure for epithelial maturation inversely correlating with invasive properties. The total number of spheroids measured is indicated below the box \& whisker plots. Median, 10-90\% distribution (box), and 95\% confidence intervals (whiskers) are indicated. (c) Inhibition of Rac family of GTPases with broad spectrum Rac-inhibitor EHT-1864 and Rac1-specific inhibitor NSC23766 block invasion at nanomolar and micromolar concentrations, respectively. (d) Western blot analyses of key regulatory genes differentially expressed in spontaneous and CSS-induced invasion. 

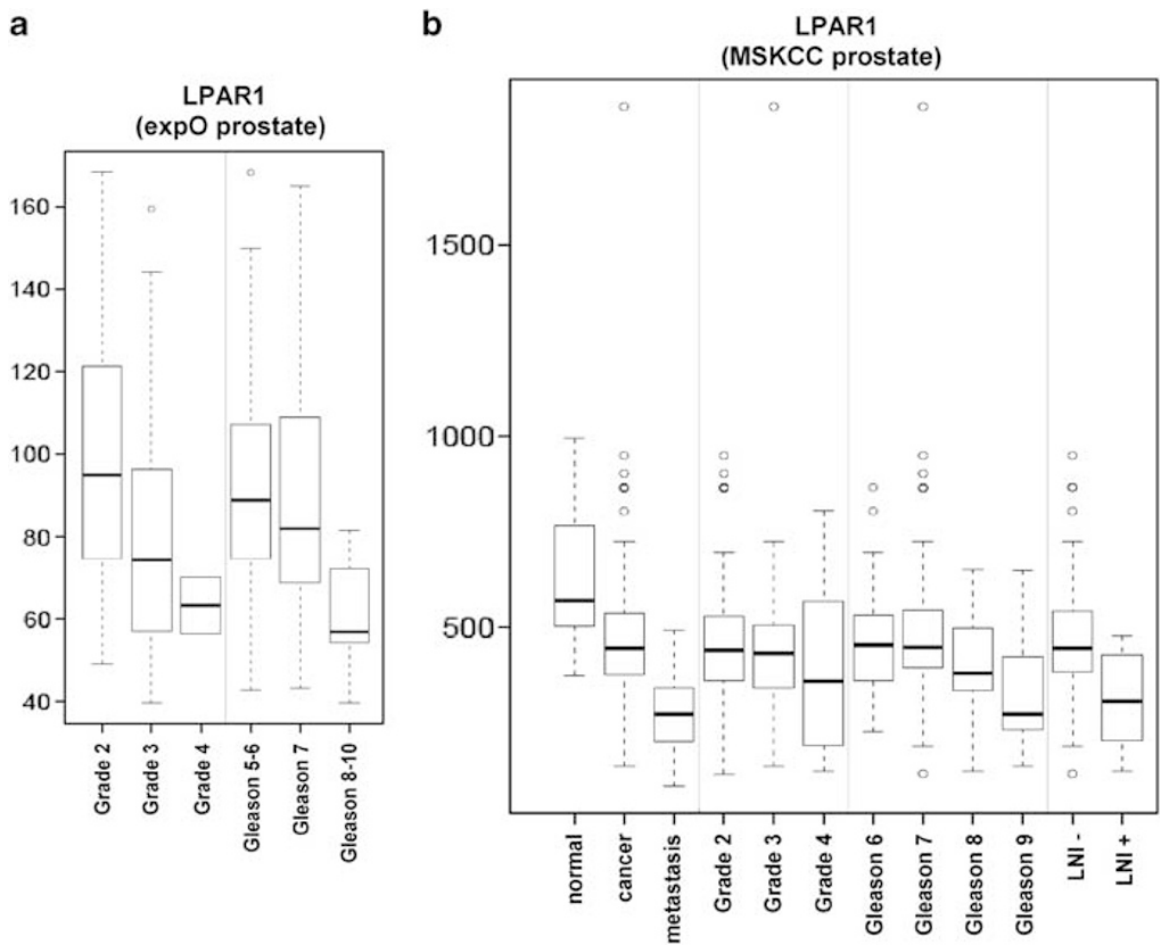

Figure 7 mRNA expression of LPA receptor 1 (LPAR1) in clinical transcriptome data sets. (a) Expression of LPAR1 in the MSKCC (Memorial Sloan Kettering Centre) data set. (b) Expression of LPAR1 in PrCas of the expO data set. Both histological grading as well as Gleason grades are indicated.

outcome (Histological grade $>3$; Gleason grade $>8$; positive lymph node invasion). LPAR1 shows further decreased expression in metastatic samples compared with primary PrCa's. In the MSKCC data, expression of LPAR 1 is significantly reduced in $42 \%$ of primary and metastatic cancers (Supplementary Figure S7A; 98 of 218 tumors). The expression of other LPA and S1P receptors like S1PR3 was also altered in PrCa's, but not as consistent as LPAR1. The heatmap (Supplementary Figure S7B) illustrates anti-correlation of LPAR1 with most other LPA/S1P receptors, except S1PR3. The high frequency of reduced LPAR1 expression and occasional deletion in PrCa's is also demonstrated in Supplementary Figure S7C. Preliminary immune histochemical staining of formalin-fixed, paraffin-embedded $\mathrm{PrCa}$ tissues with an LPAR1 antibody showed a tendency towards reduced protein expression in Gleason Grade 4-5 and metastatic lesions (Supplementary Figure S8). This is currently further explored using larger panels of sections on tissue microarrays.

\section{Discussion}

LPA and LPAR1 act as potent negative regulators of cell motility and invasion by promoting epithelial maturation, while S1P receptors and LPA receptors 2-3 preferentially promote growth and survival (Daaka, 2002). LPA and LPAR1 thus stabilize the morphology of acini, and block or delay the re-organization of the actin cytoskeleton and invadopodia formation prior to invasion. Our findings are in contrast to other reports on PrCa (Hwang et al., 2006; Evelyn et al., 2007, 2010; Hao et al., 2007; Hasegawa et al., 2008) breast or ovarian cancer (Li et al., 2009a, b), but in line with findings on melanoma (Yamaguchi et al., 2003) and colon cancers (Shida et al., 2003, 2004), which similarly suggest a role of LPA, LPAR1 and downstream RhoA/Rac pathways in epithelial maturation. The $\mathrm{G} \alpha_{12 / 13}$ pathway with downstream effectors RhoA/ROCK, and $\mathrm{G} \alpha_{\mathrm{s}}$ pathways with AC, cAMP, PKA and NF-kB are critical for the maturation of acini or spheroids. $\mathrm{G} \alpha_{12 / 13}$ is significantly induced in 3-D conditions, whereas $\mathrm{G} \alpha_{\mathrm{s}}$ is repressed across all normal and cancer-derived cell lines, including PC-3, regardless of different morphological phenotypes (Harma et al., 2010) and invasive properties. Subsequently, the activity of G-proteins and downstream effector pathways are reversed during the invasive switch of PC-3 cells, coinciding with rearrangement of the actin cytoskeleton, increased expression of SRF, formation of invadopodia and degradation of the BM. SRF activity correlates with altered F-actin structures, collagen contraction and invasion in $3-\mathrm{D}$ invasion assays (Morin et al., 2011), and integrates the expression of genes encoding structural and regulatory effectors of actin dynamics (Olson and Nordheim, 2010). Similarly, mechanisms downstream of $\mathrm{G} \alpha_{\mathrm{s}}$ (AC, intracellular cAMP levels and PKA) affect cell morphology and invasiveness. In summary, LPA, LPAR1 and pathways downstream of $\mathrm{G} \alpha_{12 / 13}, \mathrm{G} \alpha_{\mathrm{s}}$ and $\mathrm{G} \alpha_{\mathrm{i} / \mathrm{o}}$ promote multicellular differentiation of $\mathrm{PrCa}$ cells and repress 
the onset of invasiveness. These effects were most pronounced in PC-3 cells, but also observed across other transformed PrCa cell lines like LNCaP, DU145 and $22 \mathrm{rV} 1$. In contrast, inhibition of the same RhoA/ROCK and activation of cAMP-related pathways in nontransformed cells (EP156T) consistently enhanced epithelial differentiation. The complex tumor-specific nature of these cell biological effects, the activation of counteracting mechanisms, such as RhoA versus Racl in 3-D models, and the precise role of SRF and LIM kinases remain to be explored in more detail.

Most critical for understanding of these interconnected pathways related to LPA and S1P signalling is the use of appropriate model systems that properly address these mechanisms in multicellular differentiation, more similar to the (complex) clinical situation. Our finding that LPA and S1P promote differentiation has to take the tumor microenvironment, multicellular context, tissue specificity and cell transformation into account. None of the previous studies (in monolayer culture) reporting migration-promoting effects of LPA/S1P were based on organotypic, multicellular structures, and unable to track invasion of cell aggregates into the ECM. Additional studies rely on invasion models that monitor chemotactic motility of single cells, for example, Boyden chamber (Hope et al., 2009; Wang et al., 2010), or scratch/wound-healing assays (Fishman et al., 2001; Vogler et al., 2003; Wang et al., 2010). Our experimental settings focus instead on the plasticity of multicellular epithelial structures including the BM and dynamic turnover of cell-matrix contacts. In particular in PC-3 cells, this dynamic process resembles a spontaneous epithelial-to-mesenchymal transition, transforming metastable acini into mesenchymal-like, motile cell aggregates. Our results suggest a role of LPA and S1P in maturation of epithelia in general and prostate glandular cells in particular.

LPA + S1P are established as central regulators of many critical lipid-related pathways, like PPAR $\gamma$ (McIntyre et al., 2003; Zhang et al., 2004), and affected by phospholipases 2A in PrCa (Sved et al., 2004; Pineiro et al., 2010), thus linking LPA/S1P pathways to eicosanoid/arachidonic acid pathways and regulation of intracellular $\mathrm{Ca}^{2+}$. LPA was also demonstrated to induce PC-3 migration, proliferation and survival via Erk1/2 and Akt (Gibbs et al., 2009) or MAPK p38 and ERK1/2 pathways (Hao et al., 2007) - again in 2-D monolayer conditions. These studies further suggested secretion of stimulatory chemokines, activation of STAT3 (Jeong et al., 2008; Seo et al., 2010; Snider et al., 2010a) and a key role for EGFR (Snider et al., 2010b), NFkappaB and RhoA (Hwang et al., 2006) in stimulating invasion. Similar associations were reported for S1P (Sekine et al., 2010). These observations are in opposition to our experimental findings, in which $\mathrm{G} \alpha_{12 / 13}$ and RhoA clearly have an important function in stabilization of acinar structures instead.

Additionally, other controversial aspects arise, that relate to the functions of $\mathrm{LPA}+\mathrm{S} 1 \mathrm{P}$ in clinical cancers. The role of autotaxin (ENPP2) and acylglycerol kinase, both of which produce LPA from lysophosphatidylcho- line (Nouh et al., 2009; Zeng et al., 2009; Harper et al., 2010), or sphingosine kinases SHPK1 +2, which generate S1P from sphingosine (Pchejetski et al., 2008, 2010; Brizuela et al., 2010), were suggested as valid anticancer targets (Liu et al., 2009a, 2009b), together with LPAR1. However, reduced expression of LPAR1 in a large portion of primary PrCa's and distant metastases supports our observation that the LPA/LPAR1 axis actually promotes epithelial integrity and may also inhibit invasive properties in vivo. LPAR1 is unique among the LPA receptors in that it is also found in perinuclear localization and even in the nucleus (Gobeil et al., 2003; Waters et al., 2006). LPAR1 functions and intracellular transport/translocation are dependent on and regulated by RalA (Aziziyeh et al., 2009) and caveolin (Gobeil et al., 2003), related to both inflammatory and migratory mechanisms. Nuclear and perinuclear localization of LPAR1 is also regulated by cell density, Rho and ROCK inhibitors (Waters et al., 2006) and may correlate with activation of the Phospholipase A2, AKT and PI3Kinase pathways, as well as integrin signalling. Within tumor tissues, LPAR1 may be employed to allow rapid, dynamic responses to a changing microenvironment. In those tumors that express significant levels of LPAR1, this pathway might contribute to the dynamics of epithelial plasticity and sense changing interstitial levels of sphingolipids and LPA, for example, in tumor cell intravasation, extravasation and transendothelial migration (Sequeira et al., 2008; van Golen et al., 2008). Invading and circulating tumor cells may encounter changing levels of LPA, S1P and related lipid signalling molecules in interstitial, lymphoid and vascular fluids, bone marrow and lymph nodes.

In summary, bioactive lipids like LPA + S1P have a decisive role in epithelial plasticity and the regulation of epithelial-to-mesenchymal transition, cell motility and dynamic adaptation to changes in the cellular microenvironment. On the basis of an organotypic 3-D cell culture models, our findings suggest that LPAR1 functions in PrCa are considerably more complex than previously thought, and deviate from generalized motility-promoting properties. Our report puts a cautionary note on the biological function of proposed anticancer targets like LPA/S1P receptors, associated enzymes involved in generation and turnover of LPA, and some of their downstream modulators. Such targets require stringent validation studies, utilizing a panel of diverse, biologically informative and relevant model systems.

\section{Materials and methods}

Cell lines and culture conditions

Cell lines were received from ATCC or originator laboratories. All lines were propagated in RPMI-1640 (Sigma-Aldrich, St Louis, MO, USA), supplemented with 10\% FBS, 1\% penicillin/streptomycin and $1 \%$ l-glutamine. Immortalized prostate epithelial cells, EP156T and RWPE-1, were cultured in Keratinocyte Serum-Free Medium (Invitrogen, Carlsbad, CA, USA), supplemented with $50 \mathrm{mg} / 1$ bovine pituitary extract, $5 \mu \mathrm{g} / \mathrm{l} \mathrm{EGF}$ and $2 \%$ FBS for 3 -D conditions. 
$4 \mathrm{~g}$ of cell culture quality active charcoal (Sigma-Aldrich) was mixed with $40 \mathrm{mg}$ of T70 dextran (GE Healthcare, Little Chalfont, UK), $4 \mathrm{ml}$ of sterile $1 \mathrm{~m}$ Tris- $\mathrm{HCl}, 4 \mathrm{ml}$ of sterile $0.1 \mathrm{M}$ EDTA and sterile water to $400 \mathrm{ml}$. The slurry was stirred for $2-4 \mathrm{~h}$ at $+4{ }^{\circ} \mathrm{C}$, centrifuged for $20 \mathrm{~min}$ at 5000 r.p.m., and the supernatant discarded. Activated dextran-charcoal was mixed with fresh FBS, and incubated twice for $30 \mathrm{~min}$ in a shaking water bath at $+55^{\circ} \mathrm{C}$. The charcoal was pelleted by centrifugation ( $20 \mathrm{~min}, 10000$ r.p.m., $+4^{\circ} \mathrm{C}$ ), supernatant collected, sterile filtered with $0.2 \mu \mathrm{M}$ suction filters (Thermo Fisher Scientific, Waltham, MA, USA), and stored at $-20^{\circ} \mathrm{C}$.

\section{Miniaturized 3-D cell cultures and morphological image analysis with ACCA software}

Miniaturized 3-D cultures were prepared as described previously (Harma et al., 2010). Density of spheroids across all experiments was controlled by seeding defined numbers of cells in each experiment (1000 cells/well for PC-3 and 1250/well for all other cell lines). For time-lapse experiments, 3-D cultures were imaged with the automated live-cell imager IncuCyte (Essen Bioscience, Ann Arbor, MI, USA). In endpoint assays, multicellular structures were stained with calcein-AM (Invitrogen), and apoptotic/dead cells highlighted by ethidium homodimer-2 (Invitrogen). 3-D confocal images were taken with a Zeiss Axiovert-200 M microscope with Yokogawa CSU22 spinning disc confocal unit, and a Zeiss Plan-Neofluar $\times 5$ objective. Z-stacks were acquired with a step-size of $19 \mu \mathrm{m}$. Intensity projections were created with SlideBook, noise removed by normalization. Phase-contrast time-lapse and intensity projection images were analyzed with VTT's proprietary ACCA software (version 1.95). ACCA segments individual cell structures based on morphological criteria, and assigns numerical values for features like area (size), roundness (shape), roughness (contour), and measures the number and length of invasive structures (median, index and maximum extension of 'appendages'). Median cell density (cell Ratio) is quantified based on the ratio of cells to background signal. Raw numerical data were further statistically processed and visualized with $\mathrm{R} /$ Bioconductor.

\section{Immunofluorescence labelling and imaging}

Miniaturized 3-D cultures were fixed within microwells, using $2 \%$ paraformaldehyde, supplemented with $0.3 \%$ Triton X-100 (Sigma-Aldrich), $5 \mathrm{~mm}$ EGTA and $1 \mathrm{~mm} \mathrm{MgCl} 2$ for $15-20 \mathrm{~min}$ at RT. Fixed cultures were washed $3 \mathrm{x}$ with PBS, and blocked for $1 \mathrm{~h}$ with $20 \%$ horse serum. Cultures were incubated overnight at $4{ }^{\circ} \mathrm{C}$, washed with PBS and incubated for $2 \mathrm{~h}$ at RT with secondary antibodies and Hoechst nuclear stain (1:5000). AntiLaminin alpha-1 antibody (LAM-89) was purchased from Santa Cruz Biotechnology Inc. (Santa Cruz, CA, USA) anti-Ki67 antibody from Abcam (Cambridge, UK) and Alexa-conjugated phalloidin from Invitrogen.

\section{Immunoblotting}

Protein samples were collected and lysed in WB-buffer (25 mm Hepes pH 7.5, $100 \mathrm{~mm} \mathrm{NaCl}, 5 \mathrm{~mm}$ EDTA pH8.3, $0.5 \%$ Triton $\mathrm{X}-100,20 \mathrm{~mm} \beta$-glycerophosphate, $100 \mu \mathrm{M}$ orthovanadate, $0.5 \mathrm{~mm}$ PMSF and $1 \mathrm{~mm}$ DTT). Protein concentration was measured by Bradford assay, and proteins separated by SDS-PAGE with precast PAGEr gels (Lonza, Basel, Switzerland), transferred on Protran nitrocellulose transfer membrane (GE Healthcare) and blotted with primary antibodies. Phospho-CREB1 (Ser133; no. 91981) antibody was purchased from Cell Signaling Technology (Beverly, MA, USA), phospho-RhoA (p-Ser188; no. 9198) from ECMBiosciences (Versailles, KY, USA), anti-Racl (ARC03) from Cytoskeleton Inc. (Denver, CO, USA) and anti-ARHGEF11
(HPA011026), anti-ARHGAP1 (HPA004689) and anti-SRF (HPA00819) from Sigma-Aldrich.

\section{$R N A$ interference reverse transfection}

All siRNA were purchased from Qiagen (Hilden, Germany). Cells were transfected with $81 \mathrm{~nm}$ siRNA for $48-72 \mathrm{~h}$, using siLentFect (Bio-Rad Laboratories, Inc., Hercules, CA, USA) in Opti-MEM medium (Invitrogen). After transfection, cells were embedded in Matrigel. Silencing efficacy of siRNAs was validated by quantitative RT-PCR (TaqMan), as described previously (Harma et al., 2010).

\section{Drug treatments}

All compounds were purchased from Tocris Bioscience (Bristol, UK) or Sigma-Aldrich, except for Kil6425 and JTE-013 (Cayman Chemical Company, Ann Arbor, MI, USA), W146 (Avanti Polar Lipids Inc., Alabaster, AL, USA) and CCG-1423 (Merck Chemicals Ltd., Darmstadt, Germany), and dissolved in appropriate vehicle (DMSO, Ethanol, or PBS/water). Drug treatments were performed in triplicates, with 2-4 different concentrations. Lipid-depleted CSS medium was used as a positive control to promote invasion. Multicellular structures were stained and imaged by spinning disk confocal microscopy, and analyzed by ACCA, as described above.

\section{CellPlayer cell migration assays}

Confluent cultures on 96-well ImageLock plates (Essen Bioscience) were scratched with WoundMaker (Essen Bioscience) and treated with compounds for a period of $48 \mathrm{~h}$. Wound closure was monitored and quantified with IncuCyte live-cell imager (Essen Bioscience).

\section{Bioinformatics: Clinical $m R N A$ expression data analyses} Expression and correlation of LPA and S1P-related genes and pathways were analyzed in several large scale and clinical transcriptome studies: (1) The MSKCC data set containing > 240 clinical PrCa samples and metastases (Groves-Kirkby, 2010; Taylor et al., 2010) (http://www.cbioportal.org/public-portal), (2) PrCa transcriptome data from expO (NCBI GEO dataset GSE2109); and (3) experimental expression data from our panel of $\mathrm{PrCa}$ cell lines, comparing 2-D and 3-D culture (GEO accession GSE19426). Normalized raw expression data were extracted from all data sets, median centered, and analyzed through an in-house HTML interface, using R/bioconductorbased algorithms. Hierarchical and K-Means clustering for S1P- and LPA-relevant genes and downstream pathways were extracted and plotted by TreeView/Cluster (Eisen et al., 1998). Association of gene expression patterns with clinical annotation (grade, Gleason scores and TNM status) and patient survival were processed with R/Bioconductor. Gene Set Enrichment Analysis (MSigDb database) was performed across both clinical and in house datasets, to identify canonical pathways and gene ontology or GO categories enriched in clinical data and experimental settings.

\section{Conflict of interest}

The authors declare no conflict of interest.

\section{Acknowledgements}

We would like to thank Leena Saikko for expert technical assistance. This work was funded by the Academy of Finland (grant to $\mathrm{MN}$ ), number 134472 . 


\section{References}

Akbar H, Cancelas J, Williams DA, Zheng J, Zheng Y. (2006) Rational design and applications of a rac GTPase-specific small molecule inhibitor. Methods Enzymol 406: 554-565.

Aziziyeh AI, Li TT, Pape C, Pampillo M, Chidiac P, Possmayer F et al. (2009). Dual regulation of lysophosphatidic acid (LPA1) receptor signalling by ral and GRK. Cell Signal 21: 1207-1217.

Bagga S, Price KS, Lin DA, Friend DS, Austen KF, Boyce JA. (2004). Lysophosphatidic acid accelerates the development of human mast cells. Blood 104: 4080-4087.

Brekhman V, Neufeld G. (2009). A novel asymmetric 3D in-vitro assay for the study of tumor cell invasion. BMC Cancer 9: 415 .

Brizuela L, Dayon A, Doumerc N, Ader I, Golzio M, Izard JC et al. (2010). The sphingosine kinase-1 survival pathway is a molecular target for the tumor-suppressive tea and wine polyphenols in prostate cancer. FASEB J 24: 3882-3894.

Chu JH, Yu S, Hayward SW, Chan FL. (2009). Development of a three-dimensional culture model of prostatic epithelial cells and its use for the study of epithelial-mesenchymal transition and inhibition of PI3K pathway in prostate cancer. Prostate 69 428-442.

Daaka Y. (2002). Mitogenic action of LPA in prostate. Biochim Biophys Acta 1582: 265-269.

Deng W, Balazs L, Wang DA, Van Middlesworth L, Tigyi G, Johnson LR. (2002). Lysophosphatidic acid protects and rescues intestinal epithelial cells from radiation- and chemotherapy-induced apoptosis. Gastroenterology 123: 206-216.

Devine KM, Smicun Y, Hope JM, Fishman DA. (2008). S1P induced changes in epithelial ovarian cancer proteolysis, invasion, and attachment are mediated by gi and rac. Gynecol Oncol 110 237-245.

Eichholtz T, Jalink K, Fahrenfort I, Moolenaar WH. (1993). The bioactive phospholipid lysophosphatidic acid is released from activated platelets. Biochem $J$ 291(Pt 3): 677-680.

Eisen MB, Spellman PT, Brown PO, Botstein D. (1998). Cluster analysis and display of genome-wide expression patterns. Proc Natl Acad Sci U S A 95: 14863-14868.

Evelyn CR, Bell JL, Ryu JG, Wade SM, Kocab A, Harzdorf NL et al. (2010). Design, synthesis and prostate cancer cell-based studies of analogs of the Rho/MKL1 transcriptional pathway inhibitor, CCG1423. Bioorg Med Chem Lett 20: 665-672.

Evelyn CR, Wade SM, Wang Q, Wu M, Iniguez-Lluhi JA, Merajver SD et al. (2007). CCG-1423: A small-molecule inhibitor of RhoA transcriptional signaling. Mol Cancer Ther 6: 2249-2260.

Fang X, Schummer M, Mao M, Yu S, Tabassam FH, Swaby R et al. (2002). Lysophosphatidic acid is a bioactive mediator in ovarian cancer. Biochim Biophys Acta 1582: 257-264.

Fishman DA, Liu Y, Ellerbroek SM, Stack MS. (2001). Lysophosphatidic acid promotes matrix metalloproteinase (MMP) activation and MMP-dependent invasion in ovarian cancer cells. Cancer Res 61: 3194-3199.

Fourcade O, Simon MF, Viode C, Rugani N, Leballe F, Ragab A et al. (1995). Secretory phospholipase A2 generates the novel lipid mediator lysophosphatidic acid in membrane microvesicles shed from activated cells. Cell 80: 919-927.

Fukami K, Takenawa T. (1992). Phosphatidic acid that accumulates in platelet-derived growth factor-stimulated Balb/c 3T3 cells is a potential mitogenic signal. J Biol Chem 267: 10988-10993.

Gibbs TC, Rubio MV, Zhang Z, Xie Y, Kipp KR, Meier KE. (2009). Signal transduction responses to lysophosphatidic acid and sphingosine 1-phosphate in human prostate cancer cells. Prostate 69: 1493-1506

Gobeil F, Bernier SG, Vazquez-Tello A, Brault S, Beauchamp MH, Quiniou C et al. (2003). Modulation of pro-inflammatory gene expression by nuclear lysophosphatidic acid receptor type-1. J Biol Chem 278: 38875-38883.

Goetzl EJ, Dolezalova H, Kong Y, Zeng L. (1999a). Dual mechanisms for lysophospholipid induction of proliferation of human breast carcinoma cells. Cancer Res 59: 4732-4737.
Goetzl EJ, Kong Y, Mei B. (1999b). Lysophosphatidic acid and sphingosine 1-phosphate protection of $\mathrm{T}$ cells from apoptosis in association with suppression of bax. J Immunol 162: 2049-2056.

Groves-Kirkby N. (2010). Genomic profiling of prostate cancer. Nat Rev Urol 7: 420.

Guo R, Kasbohm EA, Arora P, Sample CJ, Baban B, Sud N et al. (2006). Expression and function of lysophosphatidic acid LPA1 receptor in prostate cancer cells. Endocrinology 147: 4883-4892.

Hao F, Tan M, Xu X, Han J, Miller DD, Tigyi G et al. (2007). Lysophosphatidic acid induces prostate cancer PC3 cell migration via activation of LPA(1), p42 and p38alpha. Biochim Biophys Acta 1771: 883-892.

Harma V, Virtanen J, Makela R, Happonen A, Mpindi JP, Knuuttila M et al. (2010). A comprehensive panel of threedimensional models for studies of prostate cancer growth, invasion and drug responses. PLoS One 5: e10431.

Harper K, Arsenault D, Boulay-Jean S, Lauzier A, Lucien F, Dubois CM. (2010). Autotaxin promotes cancer invasion via the lysophosphatidic acid receptor 4: Participation of the cyclic AMP/ EPAC/Racl signaling pathway in invadopodia formation. Cancer Res 70: 4634-4643.

Hasegawa Y, Murph M, Yu S, Tigyi G, Mills GB. (2008). Lysophosphatidic acid (LPA)-induced vasodilator-stimulated phosphoprotein mediates lamellipodia formation to initiate motility in PC-3 prostate cancer cells. Mol Oncol 2: 54-69.

Hong G, Baudhuin LM, Xu Y. (1999). Sphingosine-1-phosphate modulates growth and adhesion of ovarian cancer cells. FEBS Lett 460: $513-518$

Hope JM, Wang FQ, Whyte JS, Ariztia EV, Abdalla W, Long K et al. (2009). LPA receptor 2 mediates LPA-induced endometrial cancer invasion. Gynecol Oncol 112: 215-223.

Hwang YS, Hodge JC, Sivapurapu N, Lindholm PF. (2006). Lysophosphatidic acid stimulates $\mathrm{PC}-3$ prostate cancer cell matrigel invasion through activation of RhoA and NF-kappaB activity. Mol Carcinog 45: 518-529.

Inman JL, Bissell MJ. (2010). Apical polarity in three-dimensional culture systems: Where to now? J Biol 9: 2.

Jeong KJ, Park SY, Seo JH, Lee KB, Choi WS, Han JW et al. (2008). Lysophosphatidic acid receptor 2 and $\mathrm{Gi} / \mathrm{Src}$ pathway mediate cell motility through cyclooxygenase 2 expression in CAOV-3 ovarian cancer cells. Exp Mol Med 40: 607-616.

Kalluri R, Weinberg RA. (2009). The basics of epithelial-mesenchymal transition. J Clin Invest 119: 1420-1428.

Kawamori T, Osta W, Johnson KR, Pettus BJ, Bielawski J, Tanaka T et al. (2006). Sphingosine kinase 1 is up-regulated in colon carcinogenesis. FASEB J 20: 386-388.

Kim EK, Yun SJ, Do KH, Kim MS, Cho M, Suh DS et al. (2008). Lysophosphatidic acid induces cell migration through the selective activation of Akt1. Exp Mol Med 40: 445-452.

Kim J, Adam RM, Freeman MR. (2002). Activation of the erk mitogen-activated protein kinase pathway stimulates neuroendocrine differentiation in $\mathrm{LNCaP}$ cells independently of cell cycle withdrawal and STAT3 phosphorylation. Cancer Res 62: $1549-1554$.

Lee MJ, Thangada S, Liu CH, Thompson BD, Hla T. (1998a). Lysophosphatidic acid stimulates the G-protein-coupled receptor EDG-1 as a low affinity agonist. $J$ Biol Chem 273: 22105-22112.

Lee MJ, Van Brocklyn JR, Thangada S, Liu CH, Hand AR, Menzeleev $\mathrm{R}$ et al. (1998b). Sphingosine-1-phosphate as a ligand for the $G$ protein-coupled receptor EDG-1. Science 279: 1552-1555.

Li H, Wang D, Zhang H, Kirmani K, Zhao Z, Steinmetz R et al. (2009a). Lysophosphatidic acid stimulates cell migration, invasion, and colony formation as well as tumorigenesis/metastasis of mouse ovarian cancer in immunocompetent mice. Mol Cancer Ther 8 : 1692-1701. 
Li S, Huang S, Peng SB. (2005). Overexpression of G protein-coupled receptors in cancer cells: Involvement in tumor progression. Int $J$ Oncol 27: 1329-1339.

Li TT, Alemayehu M, Aziziyeh AI, Pape C, Pampillo M, Postovit LM et al. (2009b). Beta-arrestin/Ral signaling regulates lysophosphatidic acid-mediated migration and invasion of human breast tumor cells. Mol Cancer Res 7: 1064-1077.

Liu S, Murph M, Panupinthu N, Mills GB. (2009a). ATX-LPA receptor axis in inflammation and cancer. Cell Cycle 8: 3695-3701.

Liu S, Umezu-Goto M, Murph M, Lu Y, Liu W, Zhang F et al. (2009b). Expression of autotaxin and lysophosphatidic acid receptors increases mammary tumorigenesis, invasion, and metastases. Cancer Cell 15: 539-550.

Mani SA, Guo W, Liao MJ, Eaton EN, Ayyanan A, Zhou AY et al. (2008). The epithelial-mesenchymal transition generates cells with properties of stem cells. Cell 133: 704-715.

McIntyre TM, Pontsler AV, Silva AR, St Hilaire A, Xu Y, Hinshaw JC et al. (2003). Identification of an intracellular receptor for lysophosphatidic acid (LPA): LPA is a transcellular PPARgamma agonist. Proc Natl Acad Sci US A 100: 131-136.

Meyer zu Heringdorf D, Lass H, Alemany R, Laser KT, Neumann E, Zhang C et al. (1998). Sphingosine kinase-mediated $\mathrm{Ca} 2+$ signalling by G-protein-coupled receptors. EMBO $J \mathbf{1 7}$ : 2830-2837.

Mootha VK, Lindgren CM, Eriksson KF, Subramanian A, Sihag S, Lehar J et al. (2003). PGC-lalpha-responsive genes involved in oxidative phosphorylation are coordinately downregulated in human diabetes. Nat Genet 34: 267-273.

Morin P, Wickman G, Munro J, Inman GJ, Olson MF. (2011). Differing contributions of LIMK and ROCK to TGFbetainduced transcription, motility and invasion. Eur J Cell Biol 90: $13-25$.

Nava VE, Hobson JP, Murthy S, Milstien S, Spiegel S. (2002). Sphingosine kinase type 1 promotes estrogen-dependent tumorigenesis of breast cancer MCF-7 cells. Exp Cell Res 281: 115-127.

Nouh MA, Wu XX, Okazoe H, Tsunemori H, Haba R, Abou-Zeid AM et al. (2009). Expression of autotaxin and acylglycerol kinase in prostate cancer: Association with cancer development and progression. Cancer Sci 100: 1631-1638.

Olivera A, Spiegel S. (1993). Sphingosine-1-phosphate as second messenger in cell proliferation induced by PDGF and FCS mitogens. Nature 365: 557-560.

Olson EN, Nordheim A. (2010). Linking actin dynamics and gene transcription to drive cellular motile functions. Nat Rev Mol Cell Biol 11: 353-365.

Onesto C, Shutes A, Picard V, Schweighoffer F, Der CJ. (2008). Characterization of EHT 1864, a novel small molecule inhibitor of rac family small GTPases. Methods Enzymol 439: 111-129.

Pchejetski D, Bohler T, Brizuela L, Sauer L, Doumerc N, Golzio M et al. (2010). FTY720 (fingolimod) sensitizes prostate cancer cells to radiotherapy by inhibition of sphingosine kinase-1. Cancer Res 70: 8651-8661.

Pchejetski D, Doumerc N, Golzio M, Naymark M, Teissie J, Kohama $\mathrm{T}$ et al. (2008). Chemosensitizing effects of sphingosine kinase-1 inhibition in prostate cancer cell and animal models. Mol Cancer Ther 7: 1836-1845.

Pineiro R, Maffucci T, Falasca M. (2010). The putative cannabinoid receptor GPR55 defines a novel autocrine loop in cancer cell proliferation. Oncogene 30: 142-152.

Reuter JA, Ortiz-Urda S, Kretz M, Garcia J, Scholl FA, Pasmooij AM et al. (2009). Modeling inducible human tissue neoplasia identifies an extracellular matrix interaction network involved in cancer progression. Cancer Cell 15: 477-488.

Ridky TW, Chow JM, Wong DJ, Khavari PA. (2010). Invasive threedimensional organotypic neoplasia from multiple normal human epithelia. Nat Med 16: 1450-1455.

Sawada K, Morishige K, Tahara M, Ikebuchi Y, Kawagishi R, Tasaka $\mathrm{K}$ et al. (2002). Lysophosphatidic acid induces focal adhesion assembly through Rho/Rho-associated kinase pathway in human ovarian cancer cells. Gynecol Oncol 87: 252-259.
Sekine Y, Suzuki K, Remaley AT. (2010). HDL and sphingosine-1phosphate activate stat 3 in prostate cancer DU145 cells via ERK $1 / 2$ and S1P receptors, and promote cell migration and invasion. Prostate 71: 690-699.

Seo JH, Jeong KJ, Oh WJ, Sul HJ, Sohn JS, Kim YK et al. (2010). Lysophosphatidic acid induces STAT3 phosphorylation and ovarian cancer cell motility: Their inhibition by curcumin. Cancer Lett 288: $50-56$

Sequeira L, Dubyk CW, Riesenberger TA, Cooper CR, van Golen KL. (2008). Rho GTPases in PC-3 prostate cancer cell morphology, invasion and tumor cell diapedesis. Clin Exp Metastasis 25: 569-579.

Shida D, Kitayama J, Yamaguchi H, Okaji Y, Tsuno NH, Watanabe $\mathrm{T}$ et al. (2003). Lysophosphatidic acid (LPA) enhances the metastatic potential of human colon carcinoma DLD1 cells through LPA1. Cancer Res 63: 1706-1711.

Shida D, Watanabe T, Aoki J, Hama K, Kitayama J, Sonoda H et al. (2004). Aberrant expression of lysophosphatidic acid (LPA) receptors in human colorectal cancer. Lab Invest 84: 1352-1362.

Shutes A, Onesto C, Picard V, Leblond B, Schweighoffer F, Der CJ. (2007). Specificity and mechanism of action of EHT 1864, a novel small molecule inhibitor of rac family small GTPases. $J$ Biol Chem 282: $35666-35678$.

Smicun Y, Gil O, Devine K, Fishman DA. (2007). S1P and LPA have an attachment-dependent regulatory effect on invasion of epithelial ovarian cancer cells. Gynecol Oncol 107: 298-309.

Snider AJ, Orr Gandy KA, Obeid LM. (2010a). Sphingosine kinase: Role in regulation of bioactive sphingolipid mediators in inflammation. Biochimie 92: 707-715.

Snider AJ, Zhang Z, Xie Y, Meier KE. (2010b). Epidermal growth factor increases lysophosphatidic acid production in human ovarian cancer cells: Roles for phospholipase D2 and receptor transactivation. Am J Physiol Cell Physiol 298: C163-C170.

Subramanian A, Tamayo P, Mootha VK, Mukherjee S, Ebert BL, Gillette MA et al. (2005). Gene set enrichment analysis: A knowledge-based approach for interpreting genome-wide expression profiles. Proc Natl Acad Sci U S A 102: 15545-15550.

Sved P, Scott KF, McLeod D, King NJ, Singh J, Tsatralis T et al. (2004). Oncogenic action of secreted phospholipase A2 in prostate cancer. Cancer Res 64: 6934-6940.

Taylor BS, Schultz N, Hieronymus H, Gopalan A, Xiao Y, Carver BS et al. (2010). Integrative genomic profiling of human prostate cancer. Cancer Cell 18: 11-22.

Tigyi G, Miledi R. (1992). Lysophosphatidates bound to serum albumin activate membrane currents in xenopus oocytes and neurite retraction in $\mathrm{PC} 12$ pheochromocytoma cells. $J$ Biol Chem 267: 21360-21367.

Valet P, Pages C, Jeanneton O, Daviaud D, Barbe P, Record M et al. (1998). Alpha2-adrenergic receptor-mediated release of lysophosphatidic acid by adipocytes. A paracrine signal for preadipocyte growth. J Clin Invest 101: 1431-1438.

van Dijk MC, Postma F, Hilkmann H, Jalink K, van Blitterswijk WJ, Moolenaar WH. (1998). Exogenous phospholipase D generates lysophosphatidic acid and activates ras, rho and $\mathrm{Ca} 2+$ signaling pathways. Curr Biol 8: 386-392.

van Golen KL, Ying C, Sequeira L, Dubyk CW, Reisenberger T, Chinnaiyan AM et al. (2008). CCL2 induces prostate cancer transendothelial cell migration via activation of the small GTPase rac. J Cell Biochem 104: 1587-1597.

Vogler R, Sauer B, Kim DS, Schafer-Korting M, Kleuser B. (2003). Sphingosine-1-phosphate and its potentially paradoxical effects on critical parameters of cutaneous wound healing. J Invest Dermatol 120: 693-700.

Wang D, Zhao Z, Caperell-Grant A, Yang G, Mok SC, Liu J et al. (2008). S1P differentially regulates migration of human ovarian cancer and human ovarian surface epithelial cells. Mol Cancer Ther 7: 1993-2002.

Wang FQ, Ariztia EV, Boyd LR, Horton FR, Smicun Y, Hetherington JA et al. (2010). Lysophosphatidic acid (LPA) 
effects on endometrial carcinoma in vitro proliferation, invasion, and matrix metalloproteinase activity. Gynecol Oncol 117: 88-95.

Waters CM, Saatian B, Moughal NA, Zhao Y, Tigyi G, Natarajan V et al. (2006). Integrin signalling regulates the nuclear localization and function of the lysophosphatidic acid receptor-1 (LPA1) in mammalian cells. Biochem $J$ 398: 55-62.

Westermann AM, Havik E, Postma FR, Beijnen JH, Dalesio O, Moolenaar WH et al. (1998). Malignant effusions contain lysophosphatidic acid (LPA)-like activity. Ann Oncol 9: 437-442.

Yamaguchi H, Kitayama J, Takuwa N, Arikawa K, Inoki I, Takehara K et al. (2003). Sphingosine-1-phosphate receptor subtype-specific positive and negative regulation of rac and haematogenous metastasis of melanoma cells. Biochem J 374: 715-722.

Zeng Y, Kakehi Y, Nouh MA, Tsunemori H, Sugimoto M, Wu XX. (2009). Gene expression profiles of lysophosphatidic acid-related molecules in the prostate: Relevance to prostate cancer and benign hyperplasia. Prostate 69: 283-292.

Zhang C, Baker DL, Yasuda S, Makarova N, Balazs L, Johnson LR et al. (2004). Lysophosphatidic acid induces neointima formation through PPARgamma activation. $J$ Exp Med 199: 763-774.

\section{(c)}

SOMERIEHTSRE

Unported http://creativecommons.org/licenses/by-nc-sa/3.0/
This work is licensed under the Creative Commons Attribution-NonCommercial-Share Alike 3.0 License. To view a copy of this license, visit

Supplementary Information accompanies the paper on the Oncogene website (http://www.nature.com/onc) 